\title{
Clinical pharmacology of piperacillin-tazobactam combination in infants and children
}

\author{
Gian Maria Pacifici* \\ Associate Professor of Pharmacology, via Saint Andrea 32, 56127 Pisa, Italy
}

\begin{abstract}
Piperacillin is a potent antibiotic and tazobactam is an inhibitor of $\beta$-lactamase. Piperacillin-tazobactam combination has a broad spectrum of activity encompassing most gram-positive, gram-negative, aerobic and anaerobic bacteria, including many producing $\beta$-lactamase organisms. The dose of piperacillin is $90 \mathrm{mg} / \mathrm{kg}$ every 6-8 hours in infants aged 1 month to 1 year. In children, the recommended doses of piperacillin and tazobactam are $50 \mathrm{mg} / \mathrm{kg} \mathrm{and} 6.25 \mathrm{mg} / \mathrm{kg}$ or $100 \mathrm{mg} / \mathrm{kg}$ and 12.5 $\mathrm{mg} / \mathrm{kg}$, respectively, every 6 hours. Piperacillin and tazobactam are mainly excreted as unchanged drugs in the urine, and high biliary concentrations are achieved. The piperacillin elimination half-life is variable in neonates and ranges from 3.5 to 14 hours, whereas in infants aged between 1 and 6 months, the half-life is 47 min. The piperacillin-tazobactam combination is effective, safety, and well tolerated in infants and children. After a single intravenous infusion of $50 \mathrm{mg} / \mathrm{kg}$ piperacillin to infants and children aged 1 month to 12 years, the mean plasma concentrations of piperacillin rapidly decayed and were $166,76.8,42.6,24.8,9.3$, and 3.6 $\mu \mathrm{g} / \mathrm{ml}$ after $30,60,90,120,180$, and $240 \mathrm{~min}$, respectively, from dosing. In children aged 2-5 months and 6-12 years, the mean half-life is 1.4 and 0.7 hours, respectively, (p-level $=0.0003)$. The piperacillin distribution volume and clearance are not age depended. Concomitant administration of vancomycin and piperacillin-tazobactam induces acute kidney injury in infants and children, and vancomycin should not be administered to patients who are on piperacillin-tazobactam. Some bacteria may become resistant to piperacillin-tazobactam. The aim of the present study is to review the published data on piperacillin-tazobactam effects, pharmacokinetics of piperacillin and tazobactam, and bacterial resistance to piperacillin.
\end{abstract}

\section{Introduction}

Piperacillin is an ureidopenicillin originally intended as an antipseudomonal antibiotic; it is now only available as an $8: 1$ combination with the $\beta$-lactamase inhibitor tazobactam. Tazobactam is a $\beta$-lactam sulphone that possess little intrinsic antibacterial activity itself, but which has high affinity for many non-chromosomally mediated $\beta$-lactamases. The resulting piperacillin-tazobactam combination has a broad spectrum of activity encompassing most gram-positive and gram-negative aerobic and anaerobic bacteria, including many producing $\beta$-lactamase bacteria. This broad, and the role of such antibiotics in the emergence of multi-resistant Enterobacteriacae strains, make it unsuitable as first-line antibiotic therapy in early- or late-onset neonatal sepsis [1].

Piperacillin has been used in neonates since the 1980s, although degradation by bacterial $\beta$-lactamases limited its clinical usefulness as monotherapy for many infections. The half-life of piperacillin is variable and is altered by prematurity and age; in newborns, the elimination half-life ranges from 3.5 to 14 hours, whereas in infants aged between 1 and 6 months, the half-life is about $47 \mathrm{~min}$. In premature infants, the half-life is inversely proportional to gestational age, postnatal age and birth weight. Both piperacillin and tazobactam are eliminated via the kidney by glomerular filtration and tubular secretion. Piperacillin is largely excreted as unchanged substance in the urine, and $68 \%$ of the administered dose appears in the urine. Small amounts are metabolized to a minor microbiologically active desethyl metabolite. Tazobactam and its metabolite are eliminated by renal excretion, with $80 \%$ of the administered dose appearing as unchanged substance in the urine and the remaindering as the single metabolite. Piperacillin and tazobactam are also secreted into the bile. Piperacillin crosses both the inflamed and non-inflamed blood-brain barrier albeit in unpredictable amounts; however, cerebrospinal fluid penetration of the $\beta$-lactamase inhibitor tazobactam is modest; for this reason, piptazobactam is not recommended as a treatment for central nervous system infections. The combination has sodium content (5.58 mmol per 2.25 gram) and may contribute to hypernatraemia [1].

Piperacillin is used for the treatment of non-central nervous system infections, caused by susceptible $\beta$-lactamase production bacteria, including many strains of Escherichia coli, Enterobacter, Klebsiella, Haemophilus influenzae, Proteus mirabilis, Pseudomonas species, and Staphylococcus aureus and against group B Streptococcus. Piperacillin is incompatible with acyclovir, amikacin, amiodarone, amphotericin $\mathrm{B}$, azithromycin, caspofungin, dobutamine, famotidine, ganciclovir, gentamicin, netilmicin, tobramycin, and vancomycin [2].

Piperacillin extends the spectrum of ampicillin to include most strains of Pseudomonas aeruginosa, Enterobacteriacae (non- $\beta$ lactamase producing), and many Bacteroides species. Combined with a $\beta$-lactamase inhibitor (piperacillin-tazobactam), it has the broadest antibacterial spectrum of the penicillins, including activity against methicillin-susceptible Staphylococcus aureus, Haemophilus influenzae, Bacillus fragilis, and most Escherichia coli, and Klebsiella. Piperacillin is only available for parenteral administration. High biliary concentrations are achieved. Distribution into the central nervous

*Correspondence to: Gian Maria Pacifici, Associate Professor of Pharmacology, via Saint Andrea 32, 56127 Pisa, Italy, Tel: 3388250108; E-mail: pacifici44@tiscali.it

Key words: piperacillin, tazobactam, piperacillin-tazobactam, effects, pharmacokinetics, resistance, infants, children

Received: April 02, 2019; Accepted: April 23, 2019; Published: April 30, 2019 
system by piperacillin is similar to that of other penicillins, but cerebrospinal fluid concentrations of tazobactam may be inadequate to protect piperacillin against $\beta$-lactamase-producing organisms. Piperacillin is eliminated renally and requires adjustment in renal dysfunction [3].

\section{Literature search}

The literature search was performed electronically using PubMed database as search engine, the cut-off point was February 2019. The following key words: "piperacillin infants effects", "piperacillin children effects", "piperacillin infants metabolism", "piperacillin children metabolism", "piperacillin infants pharmacokinetics", "piperacillin children pharmacokinetics", "piperacillin infants resistance", and "piperacillin children resistance" were used. In addition, the books Neonatal Formulary [1] and NEOFAX by Young and Mangum [2] were consulted. The manuscript was prepared according to the "Instructions for Authors".

\section{Results}

The treatment schedule of piperacillin in neonates and infants is shown in Table 1.

\section{Efficacy and safety of piperacillin-tazobactam in infants and children}

An open, non-comparative study was designed to evaluate the safety and tolerance of parenteral piperacillin-tazobactam in verylow-birth-weight infants [4]. Twenty-seven neonates were included for nosocomial sepsis with gram-negative bacteria $(\mathrm{N}=4)$, nosocomial sepsis not responding to the empirical antibiotic regimen $(\mathrm{N}=3)$, suspected necrotizing enterocolitis $(\mathrm{N}=17)$, and infection after abdominal surgery $(\mathrm{N}=3)$. No clinical adverse events related to the study drug were noted, in particular, no cases of phlebitis, rash or stool changes. Several mild and transitory abnormalities of laboratory parameters, possibly related to piperacillin-tazobactam, were observed. No long-lasting effect on the intestinal flora was detected. Seventeen neonates $(63 \%)$ were considered to have a favourable clinical response. These results demonstrate that piperacillin-tazobactam is a safe and well tolerated drug for preterm neonates with bacterial infections, particularly those involving the gastrointestinal tract.

Piperacillin-tazobactam has been used in the neonatal intensive care unit since 1999 as part of the empirical treatment for presumed sepsis. Flidel-Rimon et al. [5] studied the microbiological and clinical efficacy and safety of piperacillin-tazobactam use in newborns with sepsis, using a retrospective analysis of medical records of all newborns treated with piperacillin-tazobactam (in association with amikacin) during 1999-2003. Piperacillin-tazobactam plus amikacin was used for 353 episodes of presumed sepsis occurring in 252 newborns: 105 episodes of presumed sepsis occurred in 100 newborns treated for 5-14 days while 248 (70\%) episodes the treatment was discontinued after

Table 1. Treatment schedule of piperacillin in neonates and infants, Neonatal Formulary [1]

\begin{tabular}{|l|c|}
\hline Neonates \\
\hline Gestational at birth $<36$ weeks \\
\hline Postnatal age $0-7$ days & $90 \mathrm{mg} / \mathrm{kg}$ every 12 hours \\
\hline Postnatal age $8-28$ days & $90 \mathrm{mg} / \mathrm{kg}$ every 8 hours \\
\hline Gestational age at birth $\geq 36$ weeks & \\
\hline Postnatal 0-7 days & $90 \mathrm{mg} / \mathrm{kg}$ every 8 hours \\
\hline Postnatal age 8-28 days & $90 \mathrm{mg} / \mathrm{kg}$ every 6 hours \\
\hline Infants & \\
\hline 1 month to 1year & $90 \mathrm{mg} / \mathrm{kg}$ every $6-8$ hours \\
\hline
\end{tabular}

2-3 days. One hundred and twenty-tree pathogens were isolated from the blood culture (40 in the 5-14 days group and 83 in those treated for 2-3 days only). There were 56 gram-negative, 55 gram-positive and 12 Candida species isolates. Klebsiella species (40\%) and Escherichia coli (30\%) were the most commonly isolated gram-negative pathogens; coagulase-negative Staphylococcus represented $95 \%$ of the grampositive pathogens isolated. Pathogen eradication was achieved within 48-72 hours of treatment in 93\% gram-negative organisms. There were no clinical, laboratory or cranial ultrasound adverse effected associated with piperacillin-tazobactam use. These authors conclude that piperacillin-tazobactam, in association with amikacin, is microbiologically and clinically efficacious and safe in the treatment of sepsis in newborns.

Piperacillin-tazobactam may safely be used in paediatric patients as an empiric treatment for serious infections in hospital environments where resistance to common first-line antimicrobials has emerged [6]. The most common indication in paediatric patients are nosocomial infections owing to resistant gram-negatives, exacerbation of pulmonary colonization with Pseudomonas aeruginosa in patients with cystic fibrosis, intra-abdominal infections, fever, neutropenia in paediatric cancer patients. The influence of piperacillin-tazobactam routine use on the selection of extended-spectrum $\beta$-lactamase producing gramnegatives and on the prevalence of vancomycin-resistant enterococci is still a matter of debate. In particular, the use of piperacillin-tazobactam in neonates and piperacillin-tazobactam monotherapy in paediatric cancer patients with fever and neutropenia should be investigated in prospective randomized studies including a sufficient number of patients.

Nosocomial Klebsiella pneumoniae infection is associated with high mortality rate in neonates and antimicrobial therapy of these infections has been complicated by the emergence of multiresistant bacteria strains. These organisms remain susceptible to only a few antimicrobial agents, and some of these are not recommended for use in children [7]. The antimicrobial agents used in the treatment of 33 neonates with Klebsiella pneumoniae infection in the tertiary neonatal unit, during an outbreak were: piperacillin-tazobactam $(\mathrm{N}=13)$, imipenem-cilastatin $(\mathrm{N}=17)$, cefotaxime $(\mathrm{N}=2)$, and ciprofloxacin $(\mathrm{N}=1)$. Extended-spectrum $\beta$-lactamase production was detected in Klebsiella pneumoniae isolates in 18 of 33 (54.5\%) neonates. All-cause mortality was 13 of $33(39.4 \%)$ and there was no significant difference in mortality rate between neonates treated with imipenem-cilastatin (6 of 17 or $35.3 \%$ ) and neonates treated with piperacillin-tazobactam (6 of 13 or $46.2 \%)$. The duration of antimicrobial therapy and total hospital stay was similar between neonates who received imipenem-cilastatin and those that received piperacillin-tazobactam. These results suggest that piperacillin-tazobactam may be a useful antimicrobial agent in neonatal infections caused by $\beta$-lactamase-producing organisms.

Piperacillin-tazobactam is an evidence-based empirical treatment of febrile neutropenia in adolescents and adults. In a retrospective, multicenter data survey, the analysis focused on safety, tolerance, and efficacy [8]. The daily administered dose of piperacillin was $240 \mathrm{mg} /$ $\mathrm{kg}$ given in three equally divided doses. Data on 156 piperacillintazobactam treatment courses in 69 infants aged $<25$ months from five paediatric cancer treatment centres (2001-2005) were analyzed. The median duration of treatment with piperacillin-tazobactam was 5 days (range, 1-23 days; 1-12 piperacillin-tazobactam courses per patient). Piperacillin-tazobactam was started on the first day of fever in $90 \%$ of all courses, in $6 \%$ in the first 72 hours, and in $4 \%$ as secondor third-line agent. Forty-five percent of all children were neutropenic. 
In all children, the outcome was favourable independent whether piperacillin-tazobactam was given as monotherapy (42 courses; $27 \%$ ) or in combination with another antibiotic. Overall, piperacillintazobactam was well tolerated and discontinued due to adverse event in only two children who experienced non-life-threatening allergic reactions (skin rash and wheezing). Piperacillin-tazobactam appears to be a safe and feasible alternative in paediatric cancer children with febrile neutropenia and in infants aged $<25$ months suggesting that the inclusion of children of all age groups in future prospective controlled studies evaluating piperacillin-tazobactam is justified.

Tazobactam-piperacillin ( $4.5 \mathrm{~g}$ for adults and $90 \mathrm{mg} / \mathrm{kg}$ for children, every 6 hours) was administered to Japanese patients with febrile neutropenia to evaluate its defervescence and clinical efficacy and safety [9]. Defervescence efficacy at day 4 of the treatment was achieved in $50 \%$ of 94 adults and $62.5 \%$ of 8 paediatric patients, respectively. The defervescence efficacy rate in relation to the neutrophil count in adults was $37.5 \%$ for the patients with a neutrophil count $<100 /$ $\mu \mathrm{l}$ and $62.5 \%$ for that between 100 and $500 / \mu \mathrm{l}$. The clinical efficacy rate at day 7 and at the end or discontinuance of the treatment was $79.6 \%$ and $59.1 \%$ in adult patients, respectively, and $57.1 \%$ and $75.0 \%$ in paediatric patients, respectively. Fifteen strains of causative bacteria were isolated in 13 adult patients at baseline. All strains were eradicated within 4 days of treatment. The side effects that occurred in adult and paediatric patients during the treatment were all known and not specific to febrile neutropenia patients. The pharmacokinetic profiles of piperacillin-tazobactam in children with febrile neutropenia are unlikely to be different from those of children with a common bacterial infection and without any immunosuppressive conditions. The study results in Japanese patients with febrile neutropenia demonstrate that piperacillin-tazobactam treatment is efficacious and safe in adults. As for paediatric patients, given the limited number of cases studied, further investigation is needed.

Aoki et al. [10] prospectively evaluated the clinical and bacteriological effects of piperacillin in children with pneumonia. Twenty-eight patients (aged 6 months to 5 years) were treated with piperacillin. In the same period, 95 strains of Haemophilus influenzae and 41 strains of Streptococcus pneumoniae were isolated and the MIC of penicillin was determined. The clinical efficacy of piperacillin was excellent in 4 cases, good in 23, and fair in 1; the response rate was $96.4 \%$ (27/28). Among the isolates there were 4 strains $(9.8 \%)$ of penicillin-susceptible Streptococcus pneumoniae, 32 strains $(78.0 \%)$ of penicillin-intermediate-resistant Streptococcus pneumoniae and 5 strains (12.2\%) of penicillin-resistant Streptococcus pneumoniae. Against Streptococcus pneumoniae, the $\mathrm{MIC}_{50}$ and $\mathrm{MIC}_{90}$ were $0.5 \mu \mathrm{g} / \mathrm{ml}$ and $2 \mu \mathrm{g} / \mathrm{ml}$, respectively. Panipenem showed the best results, followed by piperacillin, ampicillin, and flomoxef. Among the isolates, there were 51 strains $(53.7 \%)$ of $\beta$-lactamase-negative ampicillin-susceptible Haemophilus influence, 42 strains $(44.2 \%)$ of $\beta$-lactamase-negative ampicillin-resistant Haemophilus influenzae, and 1 strain $(1.1 \%)$ of $\beta$-lactamase-positive amoxicillin-clavulanic acid-resistant Haemophilus influenzae. The $\mathrm{MIC}_{50}$ and the $\mathrm{MIC}_{90}$ for piperacillin against Haemophilus were $0.0625 \mu \mathrm{g} / \mathrm{ml}$ and $0.125 \mu \mathrm{g} / \mathrm{ml}$, respectively. Piperacillin-tazobactam showed the best results, followed by panipenem, ampicillin, and flomoxef. Piperacillin proved to be very useful for the treatment of pneumoniae in children.

The combination of piperacillin with tazobactam extends the activity of piperacillin against gram-positive, gram-negative, and anaerobic bacteria. The broad-spectrum of this formulation, together with its low degree of organ toxicity observed in adults, makes piperacillin- tazobactam a tempting choice for children with radio-chemotherapyinduced neutropenia [11]. However, the use of piperacillin-tazobactam is not approved for children less than 12 years of age. The tolerability of piperacillin-tazobactam was assessed in 19 children and adolescents aged between 2 and 18 years who developed a fever during aplasia after high dose radio-chemotherapy and autologous stem cell transplantation for primary multifocal or relapsed solid tumours. Treatment with piperacillin-tazobactam was initiated on average 3 days after high dose of stem cell transplantation for primary multifocal or relapsed solid tumours. Treatment with piperacillin-tazobactam was initiated on average 3 days after high dose of stem cell transplantation, and the treatment was discontinued for approximately 10 days. Both clinical observation and laboratory studies showed no relevant alterations that would have been attributable to piperacillin-tazobactam treatment. These results indicate that piperacillin-tazobactam appears to be well tolerated in children during the acute phase of high dose of stem cell transplantation.

\section{Effects of piperacillin-tazobactam in infants and children}

Limited information indicates that piperacillin produces low levels in breast milk that are not expected to cause adverse effects in breasted infants. Occasionally disruption of the infant's gastrointestinal flora, resulting in diarrhoea or thrush has been reported with penicillins, but these effects have not been adequately valuated. Piperacillin is acceptable in nursing mothers.

The efficacy and pharmacokinetics of piperacillin monotherapy were studied in 46 children with cystic fibrosis [12]. Two children were dropped from the study within 24 hours of enrolment because of drug-associated nausea and vomiting. Initially, fourteen older children (greater than 12 years) receiving piperacillin $450 \mathrm{mg} / \mathrm{kg}$ per day underwent a preliminary evaluation. Based on these results, 30 younger children $(\leq 12$ years) randomized in a double-blind fashion received either 600 or $900 \mathrm{mg} / \mathrm{kg}$ per day of piperacillin in six equally divided doses. The half-life, distribution volume, and clearance at steadystate were similar to those obtained at the first dose. In 27 children, approximately $43 \%$ of the administered dose was recovered in the urine after 4 hours of piperacillin administration. Renal clearance averaged $49 \%$ of the total clearance. No difference in overall clinical efficacy could be identified between 600 and $900 \mathrm{mg} / \mathrm{kg}$ per day of piperacillin using two different objective scoring systems. Although a reduction in sputum of Pseudomonas colony counts was greater following the 900 $\mathrm{mg} / \mathrm{kg}$ per day regimen. In 14 children (32\%), a distinct adverse serumsicknesslike reaction was observed. The incidence of this reaction appeared to increase as the dose of piperacillin increased. All signs and symptoms of this reaction resolved within 36 hours of discontinuing piperacillin administration but recurred immediately on rechallenge in four children. All children with adverse reaction were subsequently treated with $\beta$-lactam antibiotics without ill effect. Overall, clinical improvement appeared to be independent of the piperacillin dose. These results support the use of total daily piperacillin dosage not exceeding $600 \mathrm{mg} / \mathrm{kg}$ per day.

A total of 60 children with secondary peritonitis were enrolled in an open, non-comparative multicenter study designed to evaluated the safety, tolerance, and efficacy of parenteral piperacillin-tazobactam $(80 / 10 \mathrm{mg} / \mathrm{kg}$ every 8 hours) in young children [13]. The most common diagnosis was perforated appendicitis (90\%) and the three most common pathogens, obtained from the peritoneal cavity, were Escherichia coli (52 isolates) Pseudomonas aeruginosa (16 isolates), and Bacteroides species (19 isolates). Children were examined daily 
during 4-14 days and 4-6 weeks post-therapy. Of the 60 children, 43 were evaluable. The majority of children had polymicrobial infections (36 children). All aerobic isolates were susceptible to piperacillintazobactam while 19 were resistant to piperacillin alone. Four of 43 clinically evaluable children were considered a clinical failure and 3 of 40 bacteriologically evaluable children were considered to have unfavourable microbiological response. There were 2 clinically adverse events considered related to the study drug and several possibly related, mild and transitory, abnormalities in eosinophil counts and liver function tests. These results suggest that piperacillin-tazobactam is a safe and effective combination.

Twenty children aged 1 week to 19 years with documented or suspected bacterial infections, arising outside the central nervous system, were studied. Pharmacokinetic analysis was analyzed in 15 children; 8 after the first dose, 6 during steady-state conditions, and 4 on both occasions [14]. Data were obtained utilizing noncompartmental pharmacokinetic methods. Peak piperacillin serum concentrations ranged from 51 to $232 \mu \mathrm{g} / \mathrm{ml}$ and correlated directly $(\mathrm{R}=0.75)$ with the dose administered. In children with normal renal function, there was an age-dependent decrease in elimination half-life and apparent steady-state distribution volume, whereas plasma clearance increased logarithmically. All, but 1 child, responded favourable to piperacillin therapy, and 1 child with urinary tract infection relapsed 10 days after discontinuation of the therapy. Although improved clinically, piperacillin monotherapy failed to eradicate pathogens in 2 children. No adverse clinical or biochemical effects were observed in any child.

Wiesmayr et al. [15] performed a retrospective study to critically review their experience with piperacillin-tazobactam as well as perioperative prophylactic agent in paediatric non-renal solid organ transplantation. Between 1993 and 2003 piperacillin-tazobactam was used as initial perioperative prophylaxis in 45 paediatric patients who underwent a total of 49 transplants (36 liver, 7 cardiac, 2 lung, and 4 small bowel). Median age of children was 7.9 years (range, 0.5 to 18.1 years). A total of 34 rejection episodes following 27 transplantations were diagnosed. During first hospitalization, 44 infectious episodes were observed. Bacteria were responsible for 22 episodes including sepsis $(\mathrm{N}=10)$, pneumoniae $(\mathrm{N}=5)$, wound infection $(\mathrm{N}=4)$, urinary tract infection $(\mathrm{N}=1)$, and clostridial colitis $(\mathrm{N}=2)$. The isolated organisms were gram-positive cocci $(\mathrm{N}=12)$, gram-negative rods $(\mathrm{N}=$ $3)$, non-fermentative bacilli $(\mathrm{N}=4)$, and anaerobes $(\mathrm{N}=3)$. Ten episodes were caused by piperacillin-tazobactam resistant bacteria. Twentyone of these infections were observed following antirejection therapy with pulse steroids. At later time points nine infectious episodes were successfully treated with a second course of piperacillin-tazobactam. During follow up, eight children died. Six deceased preoperatively: five from infection including aspergillosis $(\mathrm{N}=4)$, Pneumocystis jiroveci pneumoniae $(\mathrm{N}=1)$, cerebrovascular bleeding $(\mathrm{N}=1)$, and two children later on. At present, 37 children (82\%) are alive with well functioning graft after a median follow up of 39.2 (range, 0.6-123.5) months. No severe side effects caused by piperacillin-tazobactam were observed in any children. Piperacillin-tazobactam may be a suitable single agent for perioperative prophylaxis in paediatric non-renal solid organs recipient, however, a prospective comparative study is needed to make final conclusions.

Assessing the likelihood of achieving bactericidal pharmacodynamic exposures against Pseudomonas aeruginosa with intravenous antimicrobial regimens would provide insights into the selection of empiric therapy in the paediatric population. Ellis et al. [16] used the pharmacodynamic modelling to determine the likelihood of various paediatric antibiotic regimens achieving bactericidal exposure against Pseudomonas aeruginosa in children. MICs were determined for meropenem (20 and $40 \mathrm{mg} / \mathrm{kg}$ every 8 hours), imipenem (15 and $25 \mathrm{mg} / \mathrm{kg}$ every 6 hours), ceftazidime (50 mg/kg every 8 hours), cefepime ((50 mg/kg every 8 hours), and piperacillin-tazobactam (75 $\mathrm{mg} / \mathrm{kg}$ every 6 hours) against Pseudomonas aeruginosa isolates from 2-paediatric institutions. A 5000-patient Monte Carlo simulation was performed to predict attainment of pharmacodynamic targets against Pseudomonas aeruginosa for each of these regimens in a population of 10-year-olds. Optimal regimens were defined as that had a $\geq 90 \%$ likelihood of attaining target exposures. At institution 1, high-dose imipenem, high-dose meropenem, and ceftazidime achieved bactericidal pharmacodynamic exposure (likelihood of target attainment: 94\%, 92\%, and 92\%, respectively). No other regimen was associated with a high probability of attaining bactericidal exposure (low-dose imipenem, 87\%, cefepime, 85\%; low-dose meropenem, $84 \%$; piperacillin-tazobactam, $60 \%$ ). At institution 2, no regimen was associated with a high likelihood of attaining bacterial exposure; the calculated probabilities were cefepime, 78\%; ceftazidime, 65\%; highdose meropenem, 58\%; high-dose imipenem, 57\%; low-dose imipenem, $54 \%$; low-dose meropenem, $47 \%$; and piperacillin-tazobactam $47 \%$. A lack of agreement between attainment of bactericidal exposure and percent susceptibility was apparent for many regimens. Few regimens demonstrated a high likelihood of achieving bactericidal exposures against Pseudomonas aeruginosa at these institutions. Importantly, percent susceptibility overestimated attainment of the bactericidal target for some regimens, suggesting that further study is necessary in paediatric patients.

\section{Optimising piperacillin-tazobactam dosing in infants and children}

Tornoe et al. [17] performed a open-label, non-comparative, ascending single-dose, substitution study to assess the safety, tolerance and pharmacokinetics of two ascending dose levels of piperacillintazobactam, $50 \mathrm{mg} / \mathrm{kg}$ piperacillin, $6.25 \mathrm{mg} / \mathrm{kg}$ tazobactam and 100 $\mathrm{mg} / \mathrm{kg}$ piperacillin and $12.5 \mathrm{mg} / \mathrm{kg}$ administered in combination as a single $30 \mathrm{~min}$ intravenous infusion to 48 hospitalized children aged 2 months to 12 years with intraabdominal infections. Over the range of 2 months to 12 years, the mean Cmax of piperacillin ranged from $155 \mu \mathrm{g} / \mathrm{ml}$ to $181 \mu \mathrm{g} / \mathrm{ml}$ and from $344 \mu \mathrm{g} / \mathrm{ml}$ to $408 \mu \mathrm{g} / \mathrm{ml}$ after the low and high doses, respectively. Increases in the total $\mathrm{AUC}_{0 \text {-infinity }}$ were more than dose proportional. In infants aged 2 months, $\mathrm{AUC}_{0}$ values for piperacillin were $40 \%$ greater than those in children aged 6 months to 12 years. The elimination half-lives of both drugs were prolonged in infants $<6$ months of age $(1.4+0.5$ hours versus $1.6+0.5$, respectively) compared with children. The distribution volume was independent of age when normalized for weight. After correcting for weight, the clearance was reduced in children aged $<1$ to 2 years as indicated by a negative trend in the residuals. After 2 years of age, piperacillin clearance primarily depended on body weight, with an estimated weight dependency of $5.64 \mathrm{ml} / \mathrm{min} / \mathrm{kg}$. The pharmacokinetic analysis identified that piperacillin clearance increases until 2 years of age owing to the maturation process of the kidney. Since piperacillintazobactam elimination is predominantly via the kidney (about $70 \%$ renal clearance), dosing based on body weight and age will not be appropriate in premature neonates and infants $<2$ months of age owing to their immature renal function and lack of data. No empirical evidence of effectiveness in paediatrics exists for other indications (e.g. febrile neutropenia, necrotising enterocolitis, sepsis). However, it is reasonable to assume that the disease progression, response to treatment and 
exposure-response relationship are similar between paediatrics and adults since the pathophysiologic processes and bacterial pathogen in the infectious diseases that are currently approved for piperacillintazobactam use are generally similar for the two populations. Hence, a dose that renders exposure similar to those in adults at the approved dosing would be reasonable for paediatrics.

A prospective, pharmacokinetic study was conducted at the paediatric intensive care unit of the Ghent University Hospital, Ghent, Belgium, between May 2012 and March 2014 [18]. Forty-seven children aged between 1 month and 15 years were treated with intravenous piperacillin-tazobactam (Tazocin 2 grams-250 $\mathrm{mg}$ and Tazocin ${ }^{\circ} 4$ grams-500 mg). The dose of piperacillin was $75 \mathrm{mg} / \mathrm{kg}$ (maximum 4,000 $\mathrm{mg}$ ) every 6 hours. Serial blood samples were obtained from first and or assumed steady-state doses. The pharmacokinetics of piperacillintazobactam were evaluated using non-linear mixed effects modelling. One-, two-, and three-compartment disposition modes with zero input were tested to characterize the time course of plasma concentrations of both drugs independently using the ADVAN subroutines. For piperacillin, first-order, Michaelis-Menten, and first-order + MichaelisMenten elimination were also evaluated. A log-normal distribution was assumed for between-subject variability, whereas additive and proportional models (and a combination of both) were tested to describe residual variability in the data. Inter-occasion variability was tested on piperacillin clearance and distribution volume. Children younger than 2 years accounted for $42.5 \%$ of the study population $(\mathrm{N}=20)$. A twocompartment model with first-order elimination best described data of both piperacillin and tazobactam. Of note, is the fact that the effect of growth and organ maturation on the pharmacokinetics of both drugs, as demonstrated by the functions, describing the clearance of both piperacillin and tazobactam. The maturation half-life, which is the age associated with $50 \%$ maturation of clearance, and the age associated with full maturation in the present study were 5.5 months and 4.8 years respectively. When comparing the maturation parameter estimates of piperacillin versus tazobactam in the study population, it seems that maturation of tazobactam clearance was less affected when compared with piperacillin clearance, with a maturation half-life and age of full maturation. Although more data from neonates and infants are needed to estimate maturation more accurately, these observations raise questions about the impact of fixed-dose combinations of piperacillintazobactam in seriously ill young children. As $\beta$-lactam antibiotics are time-dependent antibiotics with $f \mathrm{~T}_{>\mathrm{MIC}}$ the pharmacokinetic/ pharmacodynamic parameters of interest, drug clearance, is the most important pharmacokinetic parameter related to adequate exposure. Treating infections in a seriously ill child without evidence-based dosing recommendations remains a huge challenge and may lead to increased morbidity and mortality. The present analysis challenges currently used dosing regimens $(75-100 \mathrm{mg} / \mathrm{kg}$ piperacillin every $6-8$ hours, given as short infusion) is the optimal dosing regimen. For the treatment of Pseudomonas infections, no clear-cut $f \mathrm{~T}>\mathrm{C}_{\mathrm{T}}$ target values are available for tazobactam, in combination with piperacillin. More frequent dosing, prolonged infusion and continuous infusions are dose optimization strategies for $\beta$-lactam antibiotic treatment. It should be noted that specifically chosen not to select higher amounts per dosing regimens (maximum 100-12.5 $\mathrm{mg} / \mathrm{kg}$ for piperacillin-tazobactam) is the currently recommended. This was done to mitigate potential safety risks related to higher peak concentrations, thereby avoiding the potential for saturation of the elimination processes that determine the clearance of piperacillin. This "same amount per dose" approach should also prevent a greater reduction in tazobactam clearance, as it is known that both piperacillin and tazobactam interact by competitive inhibition at the level of the tubular anion transporter system. Prolonged and continuous infusions is a preferable option whenever possible, specifically when antibiotic therapy is started empirically or when higher $f \mathrm{~T}_{>\mathrm{MIC}}$ targets are needed.

An optimal design for piperacillin-tazobactam in neonates aged $<$ 2 mounts was determined using WinPOPT Development Group New Zealand). Optimal sampling times were obtained by maximizing the determinant of Fisher information matrix based on parameters of the structural pharmacokinetic model, between-subject variability, and the residual variability [19]. The method for computing the Fisher information matrix uses a first-order approximation to the likelihood. Sampling windows were estimated around each of the sampling times in order to ensure that the design was clinically feasible. A sampling window represents a region of planned suboptimality where sampling times taken from any point within the window ensure the minimum loss of efficiency of the design. The sampling designs were evaluated by standard error of the estimate for each parameter, where the larger the standard error, the less informative the design. To compute the loss of information arising from performing a sufficient design (four sampling times derived from optimal design) versus a full design (six sampling times based on previous study), the standard errors of the parameters from the sufficient design were given by WinPopt. When evaluating the standard errors, an acceptable level of parameter precision was set as a percent standard error value of $<20 \%$ for fixed effect parameters and $<$ $50 \%$ for the variance of the random effects parameters. An individual model criterion value is also given by WinPOPT when optimizing designs. It is used for the comparison of the full designs with the sufficient designs. The greater the individual model criterion value, the better the ability of the design to estimate parameters of the model. In the present particular case, the full designs have the highest individual model criterion values. The efficiency of the design is calculated as the fraction of any two individual model criterion values. The efficacy is expressed as a percentage and provides an indication of the loss of the sufficient design to estimate the parameters of the model:

$$
\text { Efficacy }=\frac{\text { Criterion sufficient design }}{\text { Criterion full design }} \times 100 \%
$$

Compared to the full design, the sufficient design (either every 12 hours, every 8 hours, or every 6 hours) requires a minimum number of samples to produce an acceptable level of parameter precision. The optimal sampling windows for piperacillin-tazobactam are presented in Table 2. Table 3 lists the data from the assessment of expected cumulative fraction of response for piperacillin-tazobactam following administration by 5 -min and 3 -hours infusions.

Béranger et al. [20] studied the dosing regimen optimization in 50 children with a median postnatal age of 2.3 years (range, $0.1-18$ years) and median body weight of $11.9 \mathrm{~kg}$ (range, $2.7-50 \mathrm{~kg}$ ). Based on the individual pharmacokinetic parameters, median (range) time spent above one and four times the MIC was $53.3 \%(0-10)$ and $18.3 \%$ $(0-10)$, respectively. With regard to the 18 documented infections with a measured MIC, median (range) time spent above one and four times the measured MIC was 100\% (0-100) and 69.2\% (0-100), respectively. The assessment reports from the EMA (for children aged > 2 years) and FDA (for children aged $>2$ months) were evaluated. Both European and American dosing regimens resulted in subtherapeutic piperacillin concentrations. Two daily dosing regimens were $300 \mathrm{mg} /$ $\mathrm{kg}$ for normal clearance $\left(40-130 \mathrm{ml} / \mathrm{min} / 1.73 \mathrm{~m}^{-2}\right)$ and $400 \mathrm{mg} / \mathrm{kg}$ when glomerular filtration $>130 \mathrm{ml} / \mathrm{min} / 1.73 \mathrm{~m}^{-2}$. For continuous infusion, the most adequate loading dose was $25 \%$ of the daily dosing regimen, 
Table 2. Optimal sampling windows for piperacillin-tazobactam, by Chen, et al. [40]

\begin{tabular}{|c|c|c|c|c|c|c|}
\hline Drugs & Dose interval & & & Sampling times (h & & \\
\hline \multirow{6}{*}{ Piperacillin } & \multirow{2}{*}{ Every 12 - hours } & 5-min infusion & $0.1(0.1,0.12)$ & $0.31(0.26,0.41)$ & $1.35(0.97,2.91)$ & $12(7.95,11.9)$ \\
\hline & & 3-hours infusion & $0.1(0.1,0.12)$ & $0.51(0.39,0.72)$ & $3.91(2.86,4.95)$ & $12(8.94,11.9)$ \\
\hline & \multirow{2}{*}{ Every 8-hours } & 5-min infusion & $0.1(0.1,0.11)$ & $0.31(0.22,0.41)$ & $1.25(0.91,2.61)$ & $8(5.47,7.93)$ \\
\hline & & 3-hours infusion & $0.1(0.1,0.11)$ & $0.51(0.38,0.69)$ & $3.75(2.54,4.38)$ & $8(5.47,7.93)$ \\
\hline & \multirow{2}{*}{ Every 6-hours } & 5-min infusion & $0.1(0.1,0.11)$ & $0.31(0.25,0.4)$ & $1.18(0.84,1.84)$ & $8(6.86,7.95)$ \\
\hline & & 3-hours infusion & $0.1(0.1,0.11)$ & $0.50(0.37,0.62)$ & $3.6(1.82,3.97)$ & $6(4.55,5.95)$ \\
\hline \multirow{6}{*}{ Tazobactam } & \multirow{2}{*}{ Every 12 -hours } & 5-min infusion & $0.1(0.1,0.11)$ & $0.24(0.20,0.29)$ & $1.02(0.74,2.62)$ & $6(5.51,5.99)$ \\
\hline & & 3-hours infusion & $0.1(0.1,0.12)$ & $0.34(0.25,0.26)$ & $3.0(1.69,5.0)$ & $12.7(7.78,11.8)$ \\
\hline & \multirow{2}{*}{ Every 8-hours } & 5-min infusion & $0.1(0.1,0.11)$ & $0.23(0.20,0.29)$ & $0.96(0.69,1.96)$ & $8(5.56,7.95)$ \\
\hline & & 3-hours infusion & $0.1(0.1,0.11)$ & $0.34(0.20,0.48)$ & $2.68(1.51,3.82)$ & $8(6.42,7.93)$ \\
\hline & \multirow{2}{*}{ Every 6-hours } & 5-min infusion & $0.1(0.1,0.11)$ & $0.23(0.20,0.28)$ & $0.91(0.68,1.69)$ & $6(4.54,5.94)$ \\
\hline & & 3-hours infusion & $0.1(0.1,0.11)$ & $0.38(0.30,0.54)$ & $3.4(3.13,3.72$ & $6(5.57,5.99)$ \\
\hline
\end{tabular}

Table 3. Expected cumulative fraction of response for piperacillin following administration by 5 -min and 3-hours infusions, by Chen, et al. [40]

\begin{tabular}{|c|c|c|c|c|c|c|c|}
\hline \multirow[b]{2}{*}{ Pathogen } & \multirow[b]{2}{*}{ Infusion time } & \multicolumn{6}{|c|}{ Probability (\%) } \\
\hline & & $\begin{array}{c}50 \mathrm{mg} / \mathrm{kg} \text { every } 12 \\
\text { hours }\end{array}$ & $\begin{array}{c}100 \mathrm{mg} / \mathrm{kg} \text { every } \\
12 \text { hours }\end{array}$ & $\begin{array}{c}50 \mathrm{mg} / \mathrm{kg} \text { every } 8 \\
\text { hours }\end{array}$ & $\begin{array}{c}100 \mathrm{mg} / \mathrm{kg} \text { every } 8 \\
\text { hours }\end{array}$ & $\begin{array}{c}50 \mathrm{mg} / \mathrm{kg} \text { every } 6 \\
\text { hours }\end{array}$ & $\begin{array}{c}100 \mathrm{mg} / \mathrm{kg} \text { every } 6 \\
\text { hours }\end{array}$ \\
\hline \multirow{2}{*}{ Escherichia coli } & 5-min infusion & 82.41 & 92.02 & 93.85 & 95.97 & 95.41 & 96.99 \\
\hline & 3-hours infusion & 93.02 & 95.56 & 96.17 & 97.48 & 97.15 & 98.23 \\
\hline \multirow{2}{*}{$\begin{array}{c}\text { Enterobacter } \\
\text { aerogenes }\end{array}$} & 5-min infusion & 51.08 & 65.65 & 68.64 & 78.34 & 73.88 & 83.80 \\
\hline & 3-hours infusion & 66.19 & 76.26 & 77.29 & 87.69 & 84.63 & 93.19 \\
\hline \multirow{2}{*}{ Enterobacter cloacae } & 5-min infusion & 62.36 & 73.56 & 75.93 & 81.70 & 78.93 & 84.59 \\
\hline & 3-hours infusion & 74.48 & 80.49 & 80.53 & 86.52 & 84.26 & 90.99 \\
\hline \multirow{2}{*}{ Klebsiella pneumonia } & 5-min infusion & 66.40 & 79.27 & 83.34 & 87.71 & 86.71 & 89.75 \\
\hline & 3-hours infusion & 81.58 & 86.89 & 88.24 & 90.54 & 89.95 & 92.36 \\
\hline \multirow{2}{*}{ Proteus mirabilis } & 5-min infusion & 97.44 & 98.43 & 98.68 & 99.18 & 99.02 & 99.44 \\
\hline & 3-hours infusion & 98.54 & 99.08 & 99.19 & 99.58 & 99.48 & 99.778 \\
\hline \multirow{2}{*}{$\begin{array}{c}\text { Pseudomonas } \\
\text { aeruginosa }\end{array}$} & 5-min infusion & 47.78 & 62.01 & 68.13 & 77.92 & 75.47 & 82.57 \\
\hline & 3-hours infusion & 65.01 & 76.07 & 78.94 & 84.44 & 82.88 & 88.33 \\
\hline
\end{tabular}

The chosen target was $50 \% f \mathrm{~T} \geq \mathrm{MIC}$

infused over $30 \mathrm{~min}$, since it allowed rapid attainment of a sufficient concentration. According to the Monte Carlo simulations, extended or continuous infusions were adequate to attain the $50 \% f \mathrm{~T}_{\text {MIC }}$ target. Only continuous infusion allowed the $100 \% f \mathrm{~T}_{>\mathrm{MIC}}$ target to be attained. Due to the allometric rule, the probability target attainment increased with the body weight.

\section{Target attainment in children with cancer and fever treated with piperacillin-tazobactam}

A total of 43 children, aged 6 months to 18 years, with 89 fever episodes (1-4 per child), were included in the study [21]. Twenty-seven children (63\%) were males, and the median (interquartile range) for age, body weight, and glomerular filtration rate were 12 years (7-17), 39.4 $\mathrm{kg}$ (22.5-50.4), and $171.5 \mathrm{ml} / \mathrm{min} / 1.73 \mathrm{~m} 2$ (147.8-208.4), respectively. A bacteraemia was found in 6 of 43 (14\%) children, and 10 of $89(11 \%)$ had fever episodes. Of the remaining fever episodes, 10 of 89 (11\%) were caused by localized infections including central venous catheter-related infections and 69 of 89 (78\%) by fever of unknown regimen, including febrile neutropenia. Across the entire body weight range $(9.5-104.7 \mathrm{~kg})$, standard intermittent provided insufficient piperacillin concentrations and did not achieve the pharmacokinetic/pharmacodynamic targets, especially for high-MIC pathogens. Median $f \mathrm{~T}>\mathrm{MIC}$ was $61.2 \%, 53.5 \%$, and $36.3 \%$ for $\operatorname{MIC}_{50}(2.0 \mu \mathrm{g} / \mathrm{ml}), \mathrm{MIC}_{90}(4.0 \mu \mathrm{g} / \mathrm{ml})$, and breakpoint for Pseudomonas aeruginosa $(16.4 \mu / \mathrm{ml})$, respectively. Correspondingly, the median $f \mathrm{~T} 4 \mathrm{x}$ MIC was lower: $43 \%, 36.3 \%$, and $20.1 \%$. Monte Carlo simulations showed that only continuous infusion reached a probability target attainment of $95 \%$ for MIC $\leq 8 \mu \mathrm{g} / \mathrm{ml}$. Children with body weight $<25 \mathrm{~kg}$ displayed a median $f \mathrm{~T}>$ of $29.8 \%$ compared with $38.3 \%$ for children $\leq 50-75 \mathrm{~kg}$ for the target of $16.0 \mu \mathrm{g} / \mathrm{ml}$. Table 4 shows the probability of target attainment of $\mathrm{MIC}_{50}, \mathrm{MIC}_{90}$, and Pseudomonas aeruginosa breakpoint for 10 simulated dosing regimens (1) $100 \mathrm{fT}>$ $\mathrm{MIC}$ and (2) $50 \% f \mathrm{~T}<4 \times \mathrm{MIC}(\%)$.

\section{Adverse effects of piperacillin-tazobactam in children}

Bone marrow suppression is an important adverse reaction to most $\beta$-lactam antibiotics. Piperacillin-tazobactam may cause bone marrow toxicity. Reichardt et al. [22] retrospectively analyzed 100 intravenous antibiotic treatment courses (mean duration 12.5 days) in 38 children (median age 14 years) with cystic fibrosis. Of the patients receiving piperacillin-tazobactam (84\%), 6 children $(18.75 \%$ of piperacillin-tazobactam-treated children, $10.3 \%$ of piperacillintazobactam treatment courses) developed fever, malaise, and headache during treatment without signs of acute infection. In one child definite thrombocytopenia and neutropenia, in two others a milder decrease in leukocyte and thrombocyte counts was observed after the onset of fever. The events were time- and dose-dependent occurring between days 11 and 15 of treatment. Treatment courses lasted longer (14.2 versus 11.3 days; $\mathrm{p}$-level $<0.05)$ and children who had received a higher cumulative dose of piperacillin-tazobactam $(4,919+1,975 \mathrm{mg} /$ $\mathrm{kg}$ versus $3,161+1,632 \mathrm{mg} / \mathrm{kg}$; p-level $<0.02)$ in the affected group than in the untreated group. After discontinuous of piperacillin-tazobactam, fever subsided within 24 hours and blood cell counts normalized. These authors hypothesized that fever episodes and changes of blood parameters are related to piperacillin-tazobactam therapy.

Piperacillin-tazobactam is used frequently in paediatric patients with complicated appendicitis and other intra-abdominal infections. 
Table 4. Probability of target attainment of $\mathrm{MIC}_{50}, \mathrm{MIC}_{90}$, and Pseudomonas aeruginosa breakpoint for 10 simulated dosing regimens (1) $100 f \mathrm{~T}>\mathrm{MIC}$ and $(2) 50 \% f \mathrm{~T}<4 \mathrm{x} \mathrm{MIC}(\%)$, by Maarbjerg, et al. [21]

\begin{tabular}{|c|c|c|c|c|c|c|}
\hline \multirow[b]{2}{*}{ Regimen } & \multicolumn{2}{|c|}{ PTA of $\mathrm{MIC}_{50}(\mu \mathrm{g} / \mathrm{ml})$} & \multicolumn{2}{|c|}{ PTA of $\mathrm{MIC}_{90}(40 \mu \mathrm{g} / \mathrm{ml})$} & \multicolumn{2}{|c|}{ PTA of P.A. breakpoint $(16.0 \mu \mathrm{g} / \mathrm{ml})$} \\
\hline & $100 \% f \mathrm{~T}>\mathrm{MIC}$ & $50 \% f \mathrm{~T}>4 \mathrm{xMIC}$ & $\mathrm{PTA} \% f \mathrm{~T}>\mathrm{MIC}$ & $50 \% f \mathrm{~T}>4 \mathrm{xMIC}$ & $100 \% f \mathrm{~T}>\mathrm{MIC}$ & $50 \% f \mathrm{~T}>4 \mathrm{x}$ MIC \\
\hline $\begin{array}{c}\text { IA } 300 \mathrm{mg} / \mathrm{kg} / \text { day every } \\
8 \text { hours }\end{array}$ & $2.4 \%$ & $29.8 \%$ & $0.1 \%$ & $5.4 \%$ & 0 & 0 \\
\hline $\begin{array}{c}\text { IA } 300 \mathrm{mg} / \mathrm{kg} / \text { day every } \\
6 \text { hours }\end{array}$ & $16.9 \%$ & $68.4 \%$ & $2.9 \%$ & $27.9 \%$ & 0 & 0 \\
\hline $\begin{array}{c}\text { IA } 400 \mathrm{mg} / \mathrm{kg} / \text { day every } \\
8 \text { hours }\end{array}$ & $3.3 \%$ & $35.6 \%$ & $0.2 \%$ & $7.2 \%$ & 0 & 0 \\
\hline $\begin{array}{c}\text { IA } 400 \mathrm{mg} / \mathrm{kg} / \text { day every } \\
6 \text { hours }\end{array}$ & $21.0 \%$ & $76.8 \%$ & $3.6 \%$ & $35.5 \%$ & 0 & 0 \\
\hline $\begin{array}{c}\text { EI } 300 \mathrm{mg} / \mathrm{kg} / \text { day every } \\
8 \text { hours }\end{array}$ & $38.9 \%$ & $100 \%$ & $11.6 \%$ & $100 \%$ & 0 & $3.6 \%$ \\
\hline $\begin{array}{c}\text { EI } 300 \mathrm{mg} / \mathrm{kg} / \text { day every } \\
6 \text { hours }\end{array}$ & $38.9 \%$ & $100 \%$ & $11.6 \%$ & $100 \%$ & 0 & $3.6 \%$ \\
\hline $\begin{array}{c}\text { EI } 400 \mathrm{mg} / \mathrm{kg} / \text { day every } \\
8 \text { hours }\end{array}$ & $45.9 \%$ & $100 \%$ & $14.4 \%$ & $100 \%$ & 0 & $18.7 \%$ \\
\hline $\begin{array}{c}\text { EI } 400 \mathrm{mg} / \mathrm{kg} / \text { day every } \\
6 \text { hours }\end{array}$ & $82.5 \%$ & $100 \%$ & $51.1 \%$ & $100 \%$ & $1.1 \%$ & $18.7 \%$ \\
\hline CI 300 mg/kg/day & $100 \%$ & $100 \%$ & $100 \%$ & $100 \%$ & $100 \%$ & $3.5 \%$ \\
\hline CI $400 \mathrm{mg} / \mathrm{kg} / \mathrm{day}$ & $100 \%$ & $100 \%$ & $100 \%$ & $100 \%$ & $100 \%$ & $18.4 \%$ \\
\hline
\end{tabular}

IA, Intermittent administration; EI, extended infusion, CI, continuous infusion; \% $\%$ T > MIC, percentage of the dosing interval with a free maintained above MIC; PTA, probability of target attainment; P.A. breakpoint, Pseudomonas aeruginosa breakpoint

Patel et al. [23] reported 10 paediatric patients who developed a piperacillin-tazobactam-associated adverse reactions characterized by fever, rash, hematologic abnormalities, and transaminitis. Physicians should be aware this entity in children treated with a prolonged course of piperacillin-tazobactam. Prompt identification can obviate unnecessary diagnostic testing and treatment.

Yusef et al. [24] reported a significantly higher occurrence of adverse events associated with prolonged courses of piperacillin-tazobactam compared with other antimicrobial agents used for paediatric outpatient's parenteral antimicrobial therapy. These adverse events were characterized by a constellation of clinical findings including fever, hematologic abnormalities, and transaminitis. Adverse events related to piperacillin-tazobactam should be considered in children who developed a febrile illness associated with a prolonged course of therapy.

Neutropenic fever is a common complication of myelosuppressive therapy in paediatric oncology patients. Piperacillin-tazobactam is used for empiric treatment of neutropenic fever. Pratt et al. [25] described four cases of suspected piperacillin-tazobactam induced nephrotoxicity occurring in children with paediatric malignancies admitted to the hospital and treated for fever and neutropenia. All children exhibited acute renal injury shortly after piperacillin-tazobactam administration and had biopsy evidenced that renal injury was due to acute interstitial nephritis. These findings are suggestive of piperacillin-tazobactam induced nephrotoxicity in paediatric oncology children with fever and neutropenia and that piperacillin-tazobactam should be used judiciously in this population.

An 11 year-old-boy with glomerulonephritis developed acute renal failure 4 days after beginning piperacillin treatment. Renal biopsy revealed acute tubulointersitial nephritis with marked eosinophils [26]. A lymphocyte stimulation test for piperacillin demonstrated an extremely high lymphocyte stimulation test index of $626 \%$. The serum levels of immunoglobulin $\mathrm{E}$ and eosinophils cationic protein also showed a significant increase at 9,021 IU/ml and greater than $150 \mu \mathrm{g} / \mathrm{l}$, respectively. These findings suggest that a hypersensibility reaction may play a role in the pathogenesis of acute tubulointersitial nephritis.
Two cases are reported of coagulopathy in association with the administration of piperacillin with cystic fibrosis [27]. In both cases the coagulopathy was associated with the development of a serum sicknesslike illness with fever, rash, and abnormal liver function tests occurring on day 12 and day 16 of treatment, respectively. On withdrawal of piperacillin, both the serum sickness and the coagulopathy resolved rapidly, without sequelae.

\section{Concomitant administration of vancomycin and piperacillin- tazobactam induces acute kidney injury in infants and children}

Holsen et al. [28] compared risks of acute kidney injury in critically ill infants treated with vancomycin and piperacillin-tazobactam versus vancomycin and ceftriaxone. Infants aged $\geq 2$ months admitted to the paediatric intensive care unit who received $\geq 48$ hours of vancomycin and piperacillin-tazobactam or vancomycin and ceftriaxone. Acute kidney injury was defined as a minimum $50 \%$ increase in serum creatinine, adjusted for total fluid balance, from baseline over a 48hour period. Bivariate analysis compared treatment groups with acute kidney injury. A multivariable logistic regression model was fit for acute kidney injury including covariate analysis. The study included 93 infants. There were no differences between treatment groups in terms of age, severity of illness, baseline renal function, vancomycin dosing, or vancomycin trough concentrations. Infants who received vancomycin and piperacillin-tazobactam had a higher cumulative frequency of acute kidney injury than those who received vancomycin and ceftriaxone 915/58 [25.9\%] versus 3/35 [8.6\%]; p-level $=0.041$. After controlling for vancomycin trough concentration, age, concurrent nephrotoxin exposure, and use of vasopressors, exposure to piperacillin-tazobactam significantly increased the risk of acute kidney injury (adjusted odds ratio $=4.55 ; 95 \%$ confidence interval $=1.11-18.7 ; \mathrm{p}$-level $=0.035)$ compared with ceftriaxone. Use of vasopressors (adjusted odds ratio = 3.37 [ $95 \%$ confidence interval $=1.14-12.3]$ ) and a vancomycin trough $\geq$ to $15 \mathrm{mg} / \mathrm{dl}$ (adjusted odds ratio $=3.73$ [95\% confidence interval $=$ 1.14-12.3]) and a vancomycin trough $\geq 15 \mathrm{mg} / \mathrm{dl}$ (adjusted odds ratio $=4.12[95 \%$ confidence interval $=1.12 / 15.2]$ ) was also associated with acute kidney injury (median $=18.0$ days; interquartile range $=7.76$ 29.7) compared with those without acute kidney injury ( median $=6.21$ 
days; interquartile range $=7.76-29.7)$; interquartile range, $2.92-15.6$; p-level $=0.017)$. In critically ill infants, acute kidney injury occurred more in patients treated with vancomycin and piperacillin-tazobactam versus vancomycin plus ceftriaxone. After controlling for covariates, exposure to piperacillin-tazobactam was associated with an increase odds acute kidney injury development.

Vancomycin is very commonly used in combination with piperacillin-tazobactam as the empiric treatment for moderatesevere infection, whenever coverage for both methicillin-resistant Staphylococcus aureus and Pseudomonas aeruginosa is required. The combination of vancomycin and piperacillin in adults has been reported to significantly increase the acute risk of acute kidney injury relative to vancomycin monotherapy [29]. A retrospective chart review was conducted of paediatric patients, aged 0-14 years, received vancomycin and piperacillin concomitantly for 48 hours. Acute kidney injury is defined as a decrease in estimated glomerular filtration rate $\geq$ $50 \%$ from baseline. Eight children admitted to the hospital at King Saud University Medical City in Saudi Arabia and who received concomitant vancomycin and piperacillin-tazobactam treatment for pneumonia $(\mathrm{N}=7)$ or febrile neutropenia $(\mathrm{N}=1)$ developed drug-induced nephrotoxicity. Drug Interaction Probability Scale score for causation assessment was 9 in all cases (high probable). Caution in utilizing the combination of vancomycin and piperacillin-tazobactam is wanted in paediatric patients. Health-care professionals should be vigilant if this combination is to be initiated and ensure close monitoring of renal function. Antibiotic therapy descalation should be considered as soon as culture results are available.

Downes et at al. [30] assessed the risk of acute kidney injury in children during concomitant therapy with vancomycin and 1 antipseudomonal $\beta$-lactam antibiotic throughout the first week of hospitalization. These authors performed a retrospective cohort study focused on children hospitalized for 3 or more days who received vancomycin intravenously plus 1 other antipseudomonal $\beta$-lactam combination therapy. The study used the Paediatric Health Information System Plus database, which contains administrative and laboratory data from 6 paediatric hospitals in the United States. Children with underling kidney disease or abnormal serum creatinine levels on hospital days 0 to 2 were among those excluded. Children aged 6 months to 18 years were admitted through the emergency department of the hospital were included. Data analysis took place from April 2016 through July 2017. The primary outcome was acute kidney injury on hospital days 3 to 7 and within 2 days of receiving combination therapy. Acute kidney injury was defined using KDIGO criteria and was based on changes in serum creatinine level from hospital days 0 to 2 through hospital days 3 to 7 . Multiple logistic regression was performed using a discretetime failure model to test the association between acute kidney injury and receipt on intravenously vancomycin plus piperacillin-tazobactam or vancomycin plus 1 antipseudomonal $\beta$-lactam antibiotic. A total of 1,915 hospitalized children who received combination therapy were identified. Of the 1,915 children, a total of 866 (45.2\%) were female and $1,049(54.8 \%)$ were male, $1,049(54.8 \%)$ were identified as white in race/ ethnicity, and the median (interquartile range) age was 5.6 (2.1-12.7) years. Among the cohort who received intravenous vancomycin plus 1 other antipseudomonal $\beta$-lactam antibiotic, 157 children (8.2\%) had antibiotic-associated acute kidney injury. This number included 117 of 1,009 children (11.7\%) who received intravenous vancomycin plus piperacillin-tazobactam combination therapy. After adjustment for age, intensive care unit level of care, receipt of nephrotoxins, and hospital, intravenous vancomycin plus piperacillin-tazobactam combined therapy was associated with higher odds of acute kidney injury each hospital day compared with vancomycin plus 1 other antipseudomonal $\beta$-lactam antibiotic combination (adjusted odds ratio $=3.40 ; 95 \%$ confidence interval $=2 \cdot 26-5 \cdot 14)$. Coadministration of intravenous vancomycin and piperacillin-tazobactam may increase the risk of acute kidney injury in hospitalized children. Paediatricians must be cognizant of the potential risk of this combination therapy when making empirical antibiotic therapy when making empirical antibiotic choice.

Piperacillin is mainly excreted unchanged in the urine [1-3]. In literature, there are no studies on the metabolism of piperacillin in infants and children.

\section{Pharmacokinetics of piperacillin and tazobactam in infants and children}

Thirumoorthi et al. [31] administered piperacillin sodium alone or in combination with another antimicrobial agent to 9 children aged 1 month and 12 years. Piperacillin was administered intravenously as a 30-min infusion at a dose of $50 \mathrm{mg} / \mathrm{kg}$ every four hours. Venous blood specimens were sampled before the infusion of piperacillin, at the end of the infusion (30 min), and at 1, 1.5, 2, 3, and 4 hours after the beginning of the infusion. The plasma was separated from blood and used to measure piperacillin concentrations. Plasma samples were collected from 5 children after the first dose of piperacillin, from 19 children after subsequent doses of piperacillin, and from 13 children on both occasions. The plasma concentrations of piperacillin in infants and children are showed in Table 5. The mean concentrations of piperacillin, measured in 4 children, was 17.8 and $40.6 \mu \mathrm{g} / \mathrm{ml}$ in plasma and joint fluid, respectively, $150 \mathrm{~min}$ after dose, and 44.5 and $3.5 \mu \mathrm{g} /$ $\mathrm{ml}$ in plasma and cerebrospinal fluid, respectively, $105 \mathrm{~min}$ after dose. Table 6 reports the susceptibility of 19 bacteria to piperacillin which were recovered from a total of 90 paediatric patients.

Reed et al. [32] studied the pharmacokinetics of piperacillin and tazobactam in infants and children aged 2 months to 12 years, after a single-dose of $50 \mathrm{mg} / \mathrm{kg}$ piperacillin and $6.25 \mathrm{mg} / \mathrm{kg}$ tazobactam or 100 $\mathrm{mg} / \mathrm{kg}$ piperacillin and $12.5 \mathrm{mg} / \mathrm{kg}$ tazobactam. These two agents were infused intravenously. The pharmacokinetic behaviour of tazobactam is very similar to that observed for piperacillin, supporting the use of these two agents in a fixed-dose combination. Venous or arterial blood samples were obtained from an indwelling catheter immediately prior piperacillin-tazobactam administration and at $0.5,0.75,1.0,1.5$, $2,2.5,3$, and 4 hours after the beginning of the intravenous infusion. The pharmacokinetic study was performed in 47 patients aged 2 to 12 years. Peak concentrations in plasma were observed at the first 30-min sampling time. Peak and trough plasma concentrations averaged to 168 and $6 \mu \mathrm{g} / \mathrm{ml}$, respectively, of piperacillin, and 21 and $1.2 \mu \mathrm{g} / \mathrm{ml}$ of tazobactam, at the low dose, and 360 and $19 \mu \mathrm{g} / \mathrm{ml}$ of piperacillin, and 39 and $3 \mu \mathrm{g} / \mathrm{ml}$ of tazobactam, respectively, at high dose. Tables 7 and 8 summarize the kinetic parameters of piperacillin and tazobactam, respectively.

\section{Bacterial resistance to piperacillin-tazobactam in infants and children}

Ferraris et al. [33] reported the resistance of 39 Clostridium butyricum strains isolated from the faeces of preterm infants to 6 antibiotics. The resistance to piperacillin was $15 \%$.

Senel et al. [34] assessed the prevalence of urinary tract pathogens and their resistance patterns in the urine of 2,379 females and 106 males aged $<16$ years. Escherichia coli was the most common causative agent in total and among different age groups. The resistance to piperacillin was $51.8 \%$. 
Pacifici GM (2019) Clinical pharmacology of piperacillin-tazobactam combination in infants and children

Table 5. Plasma concentrations $(\mu \mathrm{g} / \mathrm{ml})$ of piperacillin in infants and children. The figures are the mean $\_\mathrm{SD}$, by Thirumoorthi, et al. [31]

\begin{tabular}{|c|c|c|c|c|c|c|}
\hline \multirow[b]{2}{*}{ Age } & \multicolumn{6}{|c|}{ Interval (min) from beginning of intravenous infusion of $50 \mathrm{mg} / \mathrm{kg}$ every 4 hours } \\
\hline & 30 & 60 & 90 & 120 & 180 & 240 \\
\hline 1 to 6 mounts & $160.7 \pm 40.3$ & ND & $63.6 \pm 21.6$ & $52.0 \pm 19.3$ & $19.5 \pm 11.9$ & $7.7 \pm 4.1$ \\
\hline 6 months to 12 years & $160.7 \pm 45.9$ & $76.8+34.3$ & $39.6 \pm 19.3$ & $21.6 \pm 12.2$ & $7.8+6.4$ & $3.1 \pm 4.1$ \\
\hline 6 months to 1 year & $134.7 \pm 41.8$ & $53.5 \pm 10.7$ & $32.0 \pm 13.8$ & $18.6 \pm 6.8$ & $9.7 \pm 5.5$ & $4.6 \pm 3.8$ \\
\hline 1 to 2 years & $148.5 \pm 30.6$ & $64.2 \pm 20.5$ & $38.8 \pm 13.6$ & $21.2 \pm 9.3$ & $8.1 \pm 5.4$ & $1.8 \pm 2.0$ \\
\hline 2 to 5 years & $175.3 \pm 49.1$ & $61.7 \pm 4.4$ & $31.9 \pm 12.9$ & $14.9 \pm 8.0$ & $4.1 \pm 2.8$ & $2.0 \pm 2.2$ \\
\hline 5 to 10 years & $177.2 \pm 36.5$ & $79.5 \pm 22.2$ & $40.8 \pm 17.9$ & $23.6 \pm 15.5$ & $7.9 \pm 9.1$ & $3.4 \pm 6.1$ \\
\hline 10 to 12 years & $199.0 \pm 46.5$ & $109.8+53.3$ & $53.3 \pm 29.7$ & $28.0 \pm 15.4$ & $8.2 \pm 6.0$ & $3.3 \pm 3.9$ \\
\hline Total & $166.2 \pm 42.2$ & $76.8 \pm 34.5$ & $42.6 \pm 20.9$ & $24.8 \pm 16.0$ & $9.3 \pm 8.1$ & $3.6 \pm 4.3$ \\
\hline
\end{tabular}

ND, not done.

Table 6. Susceptibility of various bacteria, recovered from a total of 90 paediatric patients, to piperacillin, by Thirumoorthi, et al. [31]

\begin{tabular}{|c|c|c|c|}
\hline Organisms & Number tested & Mean MIC $(\mu \mathrm{g} / \mathrm{ml})$ & Mean MBC $(\mu \mathrm{g} / \mathrm{ml})$ \\
\hline Streptococcus pyogenes & 17 & 0.04 & 0.04 \\
\hline Streptococcus pneumonia & 8 & 0.04 & 0.06 \\
\hline$\alpha$-Haemolytic streptococci & 5 & 0.06 & 0.06 \\
\hline Enterococcus & 1 & 8.0 & 8.0 \\
\hline Staphylococcus aureus & 13 & 36.0 & $>36.0$ \\
\hline \multicolumn{4}{|l|}{ Haemophilus influenzae } \\
\hline$\beta$-Lactamase negative & 8 & 0.03 & 0.03 \\
\hline$\beta$-Lactamase positive & 2 & 16.0 & 16.0 \\
\hline Bordetella bronchiseptica & 1 & 0.03 & 0.03 \\
\hline Eikenella corrodens & 1 & 0.03 & 0.03 \\
\hline Pasteurella multocida & 1 & 0.03 & 0.03 \\
\hline Moraxella & 3 & 0.06 & 0.12 \\
\hline Providencia alcalifaciens & 1 & 4.0 & 4.0 \\
\hline Pseudomonas stutzeri & 2 & 4.0 & 6.0 \\
\hline Acinetobacter Iwoffii & 2 & 8.0 & 8.0 \\
\hline Citrobacter freundii & 1 & 8.0 & 8.0 \\
\hline Enterobacter cloacae & 3 & 14.0 & 14.0 \\
\hline Pseudomonas aeruginosa & 13 & 16.0 & 32.0 \\
\hline Acinetobacter anitratus & 2 & 144.0 & 144.0 \\
\hline
\end{tabular}

Table 7. Pharmacokinetic parameters of piperacillin as a function of age. The figures are the mean $\pm \mathrm{SD}$, by Reed, et al. [32]

\begin{tabular}{|c|c|c|c|c|c|c|c|c|}
\hline Subject age & Half-life (hours) & $\begin{array}{c}V d \\
(\mathrm{~L} / \mathrm{kg})\end{array}$ & $\begin{array}{c}V_{d_{s s}} \\
(\mathrm{~L} / \mathrm{kg})\end{array}$ & $\begin{array}{c}\text { MRT } \\
\text { (hours) }\end{array}$ & $\underset{(\mathrm{ml} / \mathrm{min} / \mathrm{kg})}{\mathrm{Cl}}$ & $\underset{(\mathrm{ml} / \mathrm{min} / \mathrm{kg})}{\mathrm{Cl}_{\mathrm{R}}}$ & $\mathrm{Cl}_{\mathrm{R}}: \mathrm{CL}$ & $\begin{array}{c}\text { Fe (0-6 hour) } \\
\text { (\% dose) }\end{array}$ \\
\hline $\begin{array}{l}2-5 \text { months } \\
(\mathrm{N}=12)\end{array}$ & $1.4 \pm 0.5$ & $0.37 \pm 0.1$ & $0.33 \pm 0.1$ & $2.0 \pm 0.7$ & $3.3 \pm 0.8$ & $2.6 \pm 0.9$ & $0.72 \pm 0.2$ & $71 \pm 21$ \\
\hline $\begin{array}{l}\text { 6-23 months } \\
(\mathrm{N}=12)\end{array}$ & $0.9 \pm 0.3$ & $0.36 \pm 0.1$ & $0.30 \pm 0.1$ & $1.4 \pm 0.3$ & $4.7 \pm 1.8$ & $2.0 \pm 0.6$ & $0.46 \pm 0.2$ & $68 \pm 3.4$ \\
\hline $\begin{array}{l}2-5 \text { years } \\
(\mathrm{N}=12)\end{array}$ & $0.7 \pm 0.1$ & $0.36 \pm 0.1$ & $0.28 \pm 0.1$ & $1.1 \pm 0.2$ & $5.5 \pm 1.5$ & $3.4 \pm 1.1$ & $0.66 \pm 0.2$ & $74 \pm 15$ \\
\hline $\begin{array}{c}6-12 \text { years } \\
\mathrm{N}=11)\end{array}$ & $0.7 \pm 0.2$ & $0.36 \pm 0.2$ & $0.26 \pm 0.1$ & $1.1 \pm 0.3$ & $3.6 \pm 0.7$ & $3.6 \pm 0.7$ & $0.73 \pm 0.2$ & $72 \pm 18$ \\
\hline
\end{tabular}

$\mathrm{Vd}$, distribution volume, $\mathrm{Vd}_{\mathrm{ss}}$, distribution volume at steady-state, $\mathrm{MRT}$, mean residence time, $\mathrm{Cl}$, clearance, $\mathrm{Cl}_{\mathrm{R}}$, renal clearance, $\mathrm{Fe}$ amount of drug recovered in urine

Table 8. Pharmacokinetic parameters of tazobactam as a function of age. The figures are the mean $+\mathrm{SD}$, by Reed, et al. [32]

\begin{tabular}{|c|c|c|c|c|c|c|c|c|}
\hline Subject age & Half-life (hours) & $\begin{array}{c}\text { Vd } \\
(\mathrm{L} / \mathrm{kg})\end{array}$ & $\begin{array}{c}V_{d_{s s}} \\
(\mathrm{~L} / \mathrm{kg})\end{array}$ & $\begin{array}{c}\text { MRT } \\
\text { (hours) }\end{array}$ & $\underset{(\mathrm{ml} / \mathrm{min} / \mathbf{k g})}{\mathrm{Cl}}$ & $\underset{(\mathrm{ml} / \mathrm{min} / \mathrm{kg})}{\mathrm{Cl}_{\mathrm{R}}}$ & $\mathrm{Cl}_{\mathrm{R}}: \mathrm{CL}$ & $\begin{array}{c}\text { Fe (0-6 hour) } \\
\text { (\% dose) }\end{array}$ \\
\hline $\begin{array}{l}2-5 \text { months } \\
(\mathrm{N}=12)\end{array}$ & $1.6 \pm 0.5$ & $0.43 \pm 0.1$ & $0.39+0.1$ & $2.3 \pm 0.7$ & $3.3 \pm 0.7$ & $2.7 \pm 0.8$ & $0.8 \pm 0.17$ & $73 \pm 17$ \\
\hline $\begin{array}{l}\text { 6-23 months } \\
(\mathrm{N}=12)\end{array}$ & $1.0 \pm 0.4$ & $0.42+0.1$ & $0.37 \pm 0.1$ & $1.6 \pm 0.5$ & $4.9 \pm 1.3$ & $3.4 \pm 1.9$ & $0.65 \pm 0.24$ & $69 \pm 22$ \\
\hline $\begin{array}{l}2-5 \text { years } \\
(\mathrm{N}=12)\end{array}$ & $0.8 \pm 0.2$ & $0.38+0.1$ & $0.31 \pm 0.1$ & $1.2 \pm 0.3$ & $5.5 \pm 1.7$ & $4.6 \pm 1.5$ & $0.78 \pm 0.19$ & $92 \pm 11$ \\
\hline $\begin{array}{c}6-12 \text { years } \\
(\mathrm{N}=11)\end{array}$ & $0.9 \pm 0.4$ & $0.40+0.2$ & $0.35 \pm 0.1$ & $1.3 \pm 0.5$ & $6.2 \pm 4.5$ & $3.4 \pm 1.4$ & $0.75 \pm 0.14$ & $82 \pm 17$ \\
\hline
\end{tabular}

$\mathrm{d}$, distribution volume, $\mathrm{Vd}_{\mathrm{ss}}$, distribution volume at steady-state, $\mathrm{MRT}$, mean residence time, $\mathrm{Cl}$, clearance, $\mathrm{Cl}_{\mathrm{R}}$, renal clearance, $\mathrm{Fe}$ amount of drug recovered in urine 
Yildiz et al. [35] determined the resistance of antibiotics for complicated urinary tract infection, including urinary tract anomaly, for empirical antibiotic treatment of complicated urinary tract infection. Four hundred and twenty urine isolates were obtained from 113 children with recurrent urinary tract infection, who used prophylactic antibiotics. Reflux was found to be the most important predisposing factor for recurrent urinary tract infection (31.9\%). Renal scar was detected more in children with urinary tract anomaly than without urinary tract anomaly $(59.2 \%$ versus $12.4 \%$, p-level $<0.05)$. Gramnegative organisms were predominant in patients with and without urinary tract anomalies (91.5\% versus $79.5 \%)$. Enterococci and Candida species were more prevalent in children with urinary tract anomalies than without urinary tract anomalies $(\mathrm{p}$-level $<0.001)$. Isolates were resistant to piperacillin-tazobactam in patients with urinary tract anomalies as compared to without urinary tract anomalies.

The emergence and persistence of multidrug-resistant diarrheagenic Escherichia coli causing acute diarrhoea is a major public health challenge in developing countries. Konaté et al. [36] evaluated the resistance phenotypes of diarrheagenic Escherichia coli isolated from stool samples collected from children aged $5<$ years with acute diarrhoea. Diarrheagenic Escherichia coli strains were isolated and identified by standard microbiological methods and PCR method was used for further characterize them. The diarrheagenic Escherichia coli was resistant to piperacillin for $64.5 \%$.

The Bacteroides fragilis group constitute a significant proportion of the human gut bacteria and comprise a major proportion of anaerobic bacteria isolated in human infections. Sydenham et al. [37] established a baseline of antimicrobial susceptibility rates in Bacteroides fragilis group in the intestinal tract of relatively antibiotic-naive healthy Danish children. From 174 faecal samples collected from children attending day care, 359 non-duplicate isolates were screened for antimicrobial susceptibility. Of these, $5.0 \%$ were intermediate-susceptible to piperacillin-tazobactam.

Ibrahim et al. [38] investigated the virulence factors including haemolysin production, $\beta$-lactamase production, and biofilm formation. Antimicrobial resistance and plasmid content of 20 Escherichia coli isolates were obtained from faces and Tigris water and were screened. A total of ten clinical and ten water Escherichia coli were studied. Results showed that all Escherichia coli isolates give negative results for O157:H7. Virulence factors analysis showed that $6 / 10$ water isolates and 2/10 clinical isolates were haemolytic, 5/10 water isolates, and $4 / 10$ clinical isolates were $\beta$-lactamase producer. Antibiotics profile showed that all bacteria isolates were multidrug resistant. All Escherichia coli isolates were resistant to piperacillin. The plasmid DNA analysis showed that all Escherichia coli isolates contained with molecular weight range between $4.507 \mathrm{kbp}$ and $5.07 \mathrm{kbp}$, but clinical isolates contained multiple small and mega plasmid. The present results reveal that Escherichia coli isolates from river water exhibit a higher level of haemolysin production, $\beta$-lactamase production, and biofilm formation than faeces isolates may be due to long adaptation. On the other hand, clinical Escherichia coli isolates from faeces showed higher level of antibiotic resistance hand have multiple plasmids.

A total of 145 Escherichia coli strains causing pyelonephritis in children were investigated for the prevalence of genes encoding the following virulence factors (VFs): $\mathrm{P}$ fimbria (67.6\%), S fimbria (53.8\%), AFA adhesions (2.8\%), cytotoxic necrotizing factor 1 (37.9\%), a-haemolysin (41.4\%), and aerobactin (71.7\%) [39]. One hundred and thirty-six profiles (97.9\%) isolates harboured at least one of the virulence genes detected in the present study. Statistically significant co-occurrent presence of two VF genes was found for a-hly-cnf1, $\alpha$-hly-sfa, cnf1-sfa (p-level < 0.001), and $\alpha$-hly-pap (p-level $=0.001$ ). Twenty-six profiles of VF genes were detected in the present study. The combinations of aerpap-sfa- $\alpha$-hly were presented with the highest frequency-both of them in 28 isolates (19.3\%). The Escherichia coli strains included in this study were resistant to piperacillin for $31.7 \%$.

An eight-year (1997-2004) surveillance study of episodes of bacteraemia was conducted in an 850-bed university hospital in central Israel. Trends of incidence, resistance, age, and mortality rate were analyzed. Marchaim et al. [40] studied 6,096 patient-unique episodes of bacteraemia, of which, 2,722 (45.3\%) were nosocomial and $523(9.2 \%)$ involved children aged $<18$ years. The overall incidence of bacteraemia episodes has increased over the study years by $39 \%$ and the patient mean age by 7.5 years. Gram-negative organisms accounted for $72 \%$ of hospital-acquired cases and $69 \%$ of community-acquired cases. There was a substantial increase in the incidence of nosocomial episodes, predominantly due to gram-negative isolates, mainly Acinetobacter baumannii, Klebsiella pneumonia, and Escherichia coli. Increased resistance to broad-spectrum antibiotics was noted among gramnegative organisms, including piperacillin-tazobactam (in Klebsiella pneumonia). The all-cause mortality rate showed a significant rise. The patient age, intensive care unit stay, and hospital acquisition were independently associated with mortality rate.

Antimicrobial resistance among Viridans group of streptococci has emerged as a hindrance to effective antibiotic therapy. Rotimi et al. [41] evaluated the prevalence of antibiotic-resistant Viridans group of streptococci in healthy children. Plaque samples were collected from tooth and tongue surfaces of 102 healthy children. Susceptibility of the Viridans group of streptococci was performed by determining the MICs of 11 antibiotics using Etest. Of 540 Viridans group of streptococci isolates from both sites, $58 \%$ were from the tooth and $42 \%$ from the tongue. The most prevalent were Streptococcus salivarious (21.5\%) and Streptococci sanguis (16.3\%). Resistance to piperacillin was $34.7 \%$.

Dzierzanowska et al. [42] examined the antibiotic susceptibility of 1,792 bacterial strains isolated from hospitalized children. A total of 1,015 gram-negative rods represented by members of Enterobacteriacae family $(\mathrm{N}=770)$ and nonfermenters $(\mathrm{N}=245)$ were isolated. The most resistant strains were noticed among Klebsiella pneumoniae and Enterobacter cloacae. Twenty-five percent of these bacteria were resistant to piperacillin.

\section{Discussion}

Piperacillin is a potent antibiotic which is active against Escherichia coli, Enterobacter, Klebsiella, Haemophilus influenzae, Proteus mirabilis, Pseudomonas species, and Staphylococcus aureus, group B Streptococcus, Bacillus fragilis, and many Bacteroides species. Tazobactam is an inhibitor of $\beta$-lactamase. The combination of piperacillin and tazobactam is available in a fixed proportion of $8: 1$. The resulting piperacillin-tazobactam combination has a broad spectrum of activity encompassing most gram-positive, gram-negative, aerobic, and anaerobic bacteria, including many producing $\beta$-lactamase organisms. In infants aged 1 month to 1 year, the dose of piperacillin is $90 \mathrm{mg} / \mathrm{kg}$ every 6-8 hours [1]. In children, the recommended doses of piperacillin and tazobactam are $50 \mathrm{mg} / \mathrm{kg}$ and $6.25 \mathrm{mg} / \mathrm{kg}$, respectively, or $100 \mathrm{mg} /$ $\mathrm{kg}$ and $12.5 \mathrm{mg} / \mathrm{kg}$, respectively, every 6 hours [17]. The combination piperacillin-tazobactam is efficacy, safe, and well tolerated in infants and children and improves the clinical and bacteriological effects [4,6-11]. Reed et al. [12] administered 600 or $900 \mathrm{mg} / \mathrm{kg}$ piperacillin daily, divided in 6 doses, to 30 children aged $\leq 12$ years. These authors concluded that 
the daily dosage of $600 \mathrm{mg} / \mathrm{kg}$ is the appropriate dose for young children. Young children infected by Escherichia coli, Pseudomonas aeruginosa, and Bacteroides were treated with piperacillin-tazobactam [13]. All aerobic isolates were susceptible to piperacillin-tazobactam. Reed et al. [14] administered piperacillin to 20 children aged 1 week to 19 years. In children with normal renal function, there was an age-dependent decrease in elimination half-life and apparent steady-state distribution volume, whereas the plasma clearance increased logarithmically. Wiesmayr et al. [15] administered piperacillin-tazobactam to 45 patients who underwent surgery. The children were infected by aspergillosis, Pneumocystis jiroveci pneumoniae, and 3 children had cerebrovascular bleeding. No severe side effects caused by piperacillintazobactam were observed. Piperacillin-tazobactam may be a suitable single agent for perioperative prophylaxis in children. Ellis et al. [16] used the pharmacodynamic modelling to determine the likelihood of various paediatric antibiotic regimens achieving bacterial exposure against Pseudomonas aeruginosa in children. Optimal regimens were determined as those that had $\mathrm{a} \geq 90 \%$ likelihood of attaining target exposure. The likelihood of piperacillin-tazobactam was $60 \%$ and $47 \%$ performed by two institutions. According to 5,000-patient Monte Carlo simulation of penicillin-tazobactam is not effective in 10-yearolds children receiving $75 \mathrm{mg} / \mathrm{kg}$ every 6 hours against Pseudomonas aeruginosa.

Optimisation of piperacillin-tazobactam dosing regimen was studied by Tornoe et. al. [17], De Cock et al. [18], by Chen et al. [19], and Béranger et al. [20] in infants and children. Tornoe et al. [17] administered an intravenous single dose of $50 \mathrm{mg} / \mathrm{kg}$ piperacillin and $6.25 \mathrm{mg} / \mathrm{kg}$ tazobactam or $100 \mathrm{mg} / \mathrm{kg}$ piperacillin and $12.5 \mathrm{mg} / \mathrm{kg}$ tazobactam to children aged 2 months to 12 years. In infants aged 2 months, $\mathrm{AUC}_{0 \text {-infinity }}$ values for piperacillin were $40 \%$ greater than those in children aged 6 months to 12 years. The elimination half-lives of both drugs were prolonged in infants aged $<6$ months. After correcting for weight, the clearance was reduced in children aged $<1$ to 2 years. After 2 years of age, piperacillin clearance primarily depends on body weight. Piperacillin clearance increases until 2 years of age owing to the maturation of the kidney. Forty-seven children aged 1 month to 15 years were treated intravenously with piperacillin-tazobactam [18]. The dose of piperacillin was $75 \mathrm{mg} / \mathrm{kg}$ every 6 hours. The elimination half-life is depending on growth and organ maturation. The clearance is the most important pharmacokinetic parameter related to adequate exposure. These authors suggest that dosing regimen of $75-100 \mathrm{mg} / \mathrm{kg}$ piperacillin every 6-8 hours, given as short infusion, is the optimal regimen. An optimal design for piperacillin-tazobactam in neonates and infants aged $<2$ months was described by Chen $e$ al. [19]. A sampling window represents a region of planned suboptimal where sampling times taken from any point within the window ensure the minimum loss of efficiency of the design. Sampling designs were evaluated by standard error of the estimate for each parameter, where the larger the standard error, the less informative the design. The greater the individual model criterion value, the better the ability of the design to estimate parameters of the model. The efficiency of the design is calculated as the fraction of any two individual model criterion values and is expressed as a percentage and provides an indication of the loss of the sufficient design to estimate the parameters of the model. Compared to the full design, the sufficient design (either every 12 hours, every 8 hours, or every 6 hours) requires minimum of samples to produce an acceptable level of parameter precision. Béranger et al. [20] studied the dosing regimen optimization in 50 children with a median postnatal age of 2.3 years. Two daily dosing regimens were $300 \mathrm{mg} / \mathrm{kg}$ for normal clearance (40$130 \mathrm{ml} / \mathrm{min} / 1,73 \mathrm{~m}^{-2}$ ) and $400 \mathrm{mg} / \mathrm{kg}$ when the glomerular filtration was
$>130 \mathrm{ml} / \mathrm{min} / 1.73 \mathrm{~m}^{-2}$ ). For continuous infusion, the most adequate loading dose was $25 \%$ of the daily dosing regimen, infused over $30 \mathrm{~min}$. According to the Monte Carlo simulations, extended or continuous were adequate to attain the $50 \% f \mathrm{~T}_{\mathrm{MIC}}$ target. Only continuous infusion allowed the $100 \% f \mathrm{~T}_{>\mathrm{MIC}}$.

Maarbjerg et al. [21] described the target attainment in children with cancer and fever treated with piperacillin-tazobactam. A total of 43 children aged 6 months to 18 years and weighting a mean of $39.4 \mathrm{~kg}$ were included in the study. Across the entire body weight $(9.5-104.7 \mathrm{~kg})$ the standard intermittent provided insufficient piperacillin concentrations and did not achieve the pharmacokinetic/pharmacodynamic targets, especially for high-MIC pathogens. For the target of $100 \% f \mathrm{~T}>\mathrm{MIC}$, median $f \mathrm{~T}>\mathrm{MIC}$ was $60.2 \%, 53.5 \%$, and $36.3 \%$ for $\mathrm{MIC}_{50}(2.0 \mu \mathrm{g} /$ $\mathrm{ml}), \mathrm{MIC}_{90}(4.0 \mu \mathrm{g} / \mathrm{ml})$, and Pseudomonas aeruginosa $(16.4 \mu \mathrm{g} / \mathrm{ml})$, respectively. Children with body weight $<25 \mathrm{~kg}$ displayed a median $f \mathrm{~T}$ $>$ of $29.8 \%$ compared with $38.3 \%$ for children $\leq 50-75 \mathrm{~kg}$ for the target of $16.0 \mu \mathrm{g} / \mathrm{ml}$.

Piperacillin-tazobactam are safe and well tolerated in infants and children. Thus, the adverse effects of piperacillin-tazobactam are limited in children, occur in a small percentage of children, and no adverse events are reported in infants. Reichardt et al. [22] administered piperacillin-tazobactam to children with median age of 14 years and cystic fibrosis. The mean duration of therapy was 12.5 days. A percentage of 18.75 children developed fever, malaise, and headache during treatment without signs of acute infection. The adverse events were time- and dose dependent occurring between days 11 and 15 of treatment. After discontinuous of piperacillin-tazobactam, fever subsided within 24 hours and blood cell counts normalized. Patel et al. [23] reported 10 paediatric patients who developed a piperacillintazobactam-associated adverse reactions characterized by fever, rash, hematologic abnormalities, and transaminitis. Yusef et al. [24] reported a significantly occurrence of adverse events associated with prolonged courses of piperacillin-tazobactam compared with other antimicrobial agents used for paediatric parenteral antimicrobial therapy. The adverse events were characterized by fever, hematologic abnormalities, and transaminitis. Pratt et al. [25] described four cases of suspected piperacillin-tazobactam induced nephrotoxicity occurring in children with paediatric malignancies admitted to the hospital and treated for fever and neutropenia. All children exhibited acute renal injury, shortly after piperacillin-tazobactam therapy, which was caused by acute interstitial nephritis. An 11 year-old-boy with glomerulonephritis developed renal failure 4 days after beginning piperacillin treatment [26]. The renal failure was caused by acute tubulointersitial nephritis. Two cases of coagulopathy associated with the administration of piperacillin are reported by Rye et al. [27]. The coagulopathy was associated with the development of a serum sickness-like illness with fever, rash, and abnormal liver function tests occurring on days 12 and 16 of treatment. On withdrawal of piperacillin, the adverse events resolved rapidly. In literature, no adverse effect is reported in infants.

The concomitant administration of vancomycin and piperacillintazobactam induces acute kidney injury in infants and children [28-30]. Vancomycin should not be administered to infants and children who are on piperacillin-tazobactam. Paediatricians must be cognizant of the potential risk of vancomycin and piperacillin-tazobactam combination therapy when making empirical antibiotic choice.

Piperacillin is mainly excreted unchanged in the urine [1-3]. In literature, there are no studies on the metabolism of piperacillin in infants and children. 
Thirumoorthi et al. [31] administered $50 \mathrm{mg} / \mathrm{kg}$ piperacillin by 30 min intravenously infusion to 9 children aged 1 month and 12 years. The plasma concentration of piperacillin rapidly decreased and averaged to $166.2 \mu \mathrm{g} / \mathrm{ml}, 42.6 \mu \mathrm{g} / \mathrm{ml}$, and $3.6 \mu \mathrm{g} / \mathrm{ml} \mathrm{30}$, 90 and $240 \mathrm{~min}$, respectively, from the beginning of piperacillin dosing.

Reed et al. [32] administered piperacillin and tazobactam intravenously at doses of $50 \mathrm{mg} / \mathrm{kg}$ and $6.25 \mathrm{mg} / \mathrm{kg}$, respectively, or $100 \mathrm{mg} / \mathrm{kg}$ and $12.5 \mathrm{mg} / \mathrm{kg}$, respectively, and investigated the pharmacokinetics of these two drugs in 47 infants and children aged 2 months to 12 years. Piperacillin elimination half-life averaged from 1.4 to 0.7 hours, in infants aged 2-5 months and in children aged 6-12 years respectively, $(\mathrm{p}$-level $=0.003)$. The distribution volume, and total body clearance were not aged dependent. The renal clearance averaged to 2.6 and $3.6 \mathrm{ml} / \mathrm{min} / \mathrm{kg}$ in infants aged $2-5$ months and in children aged 6-12 years, respectively, (p-level $<0.0001$ ). The aged depending decrease of half-life and increasing renal clearance are due to kidney maturation with the age. The pharmacokinetic behaviour of tazobactam was similar to that of piperacillin.

Some bacteria may become resistant to piperacillin-tazobactam. Clostridium butyricum [33], Escherichia coli [34-39], Enterococci and Candida species [35], Bacteroides fragilis, Acinetobacter baumannii, and Klebsiella pneumoniae [40], Viridans group of streptococci [41], and Enterobacteriacae family [42] and the resistance to piperacillintazobactam ranged from $15 \%$ to $64.5 \%$.

In conclusion, piperacillin is a potent antibiotic and tazobactam is a $\beta$-lactamase inhibitor. The fixed proportion of piperacillin and tazobactam is $8: 1$. Piperacillin-tazobactam combination has a broad spectrum of activity encompassing most gram-positive, gram-negative, aerobic and anaerobic bacteria, including many producing $\beta$-lactamase organisms. Piperacillin extends the spectrum of ampicillin including most strains of Pseudomonas aeruginosa, Enterobacteriacae, and many Bacteroides species. The recommend doses of piperacillin are $90 \mathrm{mg} / \mathrm{kg}$ every 6-8 hours in infants aged 1 month to 1 year, and 50 or $100 \mathrm{mg} /$ kg every 6 hours in children. The elimination half-life and the renal clearance of piperacillin and tazobactam are age-depended. The halflives of these two drugs decrease with age and their renal clearance increases with aging. The above described pharmacokinetic behaviours reflect the renal excretory maturation. The piperacillin-tazobactam combination is safe and well tolerated in infants and children and few adverse effects are reported in children and no adverse event is reported in infants. The standard intermittent dosing of piperacillin-tazobactam does not achieve the pharmacokinetic/pharmacodynamic targets, only continuous infusion allowed a $100 \% f T>$ MIC. Concomitant administration of vancomycin and piperacillin-tazobactam induces an acute kidney injury and vancomycin should not be administered to infants and children who are on piperacillin-tazobactam. Some bacteria may become resistant to piperacillin-tazobactam.

\section{Conflicts of interest}

The author declares no conflicts of financial interest in any product or service mentioned in the manuscript, including grants, equipment, medications, employments, gifts and honoraria.

This article is a review and drugs have not been administered to men or animals.

\section{Acknowledgments}

The author thanks Dr. Patrizia Ciucci and Dr. Francesco Varricchio, of the Medical Library of the University of Pisa, for retrieving the scientific literature.

\section{References}

1. Neonatal Formulary (2015) The Atrium, $7^{\text {th }}$ Eds John Wiley \& Sons, Ltd, Southern Gate, Chichester, West Sussex, PO19 8SQ, UK, pp: 407-408.

2. Young TE, Mangum B (2010) NEOFAX. Antimicrobials. Penicillin G. $23^{\text {rd }}$ Eds Thomson Reuters. pp 82-83.

3. MacDougall C (2018) Penicillins, cephalosporins, and other ß-lactam antibiotics. In the Goodman \& Gilman's The Pharmacological Basis of Therapeutics. $13^{\text {th }}$ Ed. In Brunton LL, Hilal-dandan, Knollmann BC. Mc Graw Hill, New York, pp, 1030.

4. Berger A, Kretzer V, Apfalter P, Rohrmeister K, Zaknun D, et al. (2004) Safety evaluation of piperacillin/tazobactam in very low birth weight infants. $J$ Chemother 16: 166-171. [Crossref]

5. Flidel-Rimon O, Friedman S, Leibovitz E, Shinwell ES (2006) The use of piperacillin/ tazobactam (in association with amikacin) in neonatal sepsis: efficacy and safety data. Scand J Infect Dis 38: 36-42. [Crossref]

6. Wolf MF, Simon A (2009) The use of piperacillin-tazobactam in neonatal and paediatric patients. Expert Opin Drug Metab Toxicol 5: 57-69. [Crossref]

7. Pillay T, Pillay DG, Adhikari M, Sturm AW (1998) Piperacillin/tazobactam in the treatment of Klebsiella pneumoniae infections in neonates. Am J Perinatol 15: 47-51. [Crossref]

8. Simon A, Lehrnbecher T, Bode U, Groll AH, Tramsen L, et al. (2007) Piperacillintazobactam in pediatric cancer patients younger than 25 months: a retrospective multicenter survey. Eur J Clin Microbiol Infect Dis 26: 801-806. [Crossref]

9. Tamura K, Akiyama N, Kanda Y, Saito M (2015) Efficacy and safety of tazobactam/ piperacillin as an empirical treatment for the patients of adult and child with febrile neutropenia in Japan. J Infect Chemother 21: 654-662. [Crossref]

10. Aoki M, Fukao T, Kaneko H, Mizunaga S, Mitsuyama J, et al. (2007) Clinical and bacteriological evaluation of the efficacy of piperacillin in children with pneumonia. $J$ Infect Chemother 13: 224-229. [Crossref]

11. Nürnberger W, Bönig H, Burdach S, Göbel U (1998) Tolerability of piperacillin/ tazobactam in children and adolescents after high dose radio-/chemotherapy and autologous stem cell transplantation. Infection 26: 65-67. [Crossref]

12. Reed MD, Stern RC, Myers CM, Klinger JD, Yamashita TS, et al. (1987) Therapeutic evaluation of piperacillin for acute pulmonary exacerbations in cystic fibrosis. Pediatr Pulmonol 3: 101-109. [Crossref]

13. Arguedas A, Sifuentes-Osornio J, Loaiza C, Herrera M, Corrales JC, et al. (1996) An open, multicenter clinical trial of piperacillin/tazobactam in the treatment of pediatric patients with intra-abdominal infections. $J$ Chemother 8: 130-136. [Crossref]

14. Reed MD, Myers CM, Yamashita TS, Blumer JL (1986) Developmental pharmacology and therapeutics of piperacillin in gram-negative infections. Dev Pharmacol Ther 9:102-114. [Crossref]

15. Wiesmayr S, Stelzmueller I, Mark W, Muehlmann G, Tabarelli W, et al. (2007) Experience with the use of piperacillin-tazobactam in pediatric non-renal solid organ transplantation. Pediatr Transplant 11: 38-48. [Crossref]

16. Ellis JM, Kuti JL, Nicolau DP (2005) Use of Monte Carlo simulation to assess the pharmacodynamics of beta-lactams against Pseudomonas aeruginosa infections in children: a report from the OPTAMA program. Clin Ther 27: 1820-1830. [Crossref]

17. Tornøe CW, Tworzyanski JJ, Imoisili MA, Alexander JJ, Korth-Bradley JM, et al. (2007) Optimising piperacillin/tazobactam dosing in paediatrics. Int $J$ Antimicrob Agents 30: 320-324. [Crossref]

18. De Cock PAJG, van Dijkman SC, de Jaeger A, Willems J, Carlier M, et al. (2017) Dose optimization of piperacillin/tazobactam in critically ill children. $J$ Antimicrob Chemother 72: 2002-2011. [Crossref]

19. Chen Y, Lu J, Dong M, Wu D, Zhu Y, et al. (2016) Target attainment analysis and optimal sampling designs for population pharmacokinetic study on piperacillin/tazobactam in neonates and young infants. Eur J Clin Pharmacol 72: 1479-1488. [Crossref]

20. Béranger A, Benaboud S, Urien S (2019) Piperacillin Population Pharmacokinetics and Dosing Regimen Optimization in Critically Ill Children with Normal and Augmented Renal Clearance. Clin Pharmacokinet 58: 223-233. [Crossref]

21. Maarbjerg SF, Thorsted A, Kristoffersson A, Friberg LE, Nielsen EI, et al. (2019) Piperacillin pharmacokinetics and target attainment in children with cancer and fever: Can we optimize our dosing strategy? Pediatr Blood Cancer 2: e27654. [Crossref] 
22. Reichardt P, Handrick W, Linke A, Schille R, Kiess W (1999) Leukocytopenia, thrombocytopenia and fever related to piperacillin/tazobactam treatment--a retrospective analysis in 38 children with cystic fibrosis. Infection 27: 355-356. [Crossref]

23. Patel A, Mao KR, McNeil JC, Kaplan SL, Vallejo JG (2015) Fever and Reversible Laboratory Abnormalities Associated with Prolonged Use of Piperacillin-Tazobactam in Children. Pediatr Infect Dis J 34: 849-850. [Crossref]

24. Yusef D, Gonzalez BE, Foster CB, Goldfarb J, Saracusa C, et al. (2017) PiperacillinTazobactam-induced Adverse Drug Events in Pediatric Patients on Outpatient Parenteral Antimicrobial Therapy. Pediatr Infect Dis J 36: 50-52. [Crossref]

25. Pratt JA, Stricherz MK, Verghese PS, Burke MJ (2014) Suspected piperacillintazobactam induced nephrotoxicity in the pediatric oncology population. Pediatr Blood Cancer 61: 366-368. [Crossref]

26. Tanaka H, Waga S, Kakizaki Y, Tateyama T, Koda M, et al. (1997) Acute tubulointerstitia nephritis associated with piperacillin therapy in a boy with glomerulonephritis. Acta Paediatr Jpn 39: 698-700.

27. Rye PJ, Roberts G, Staugas RA, Martin AJ (1994) Coagulopathy with piperacillin administration in cystic fibrosis: two case reports. J Paediatr Child Health 30: 278-279.

28. Holsen MR, Meaney CJ, Hassinger AB, Fusco NM (2017) Increased risk of acute kidney injury in critically ill children treated with vancomycin and piperacillintazobactam. Pediatr Crit Care Med 18: e585-e591.

29. Abouelkheir M,Alsubaie S (2018) Pediatric acute kidney injury induced by concomitant vancomycin and piperacillin-tazobactam. Pediatr Int 60: 136-141. [Crossref]

30. Downes KJ, Cowden C, Lasking BL, Huanga YS, Gong W, et al. (2017) Association of acute kidney injury with concominant vancomycin and piperacillin-tazobactam treatment among hospitalized children. JAMA Pediatr 171: e173219.

31. Thirumoorthi MC, Asmar BI, Buckley JA, Bollinger RO, Kauffman RE, et al. (1983) Pharmacokinetics of intravenously administered piperacillin in preadolescent children J Pediatr 102: 941-946.

32. Reed MD, Goldfarb J, Yamashita TS, Lemon E, Blumer JL (1994) Single-dose pharmacokinetics of piperacillin and tazobactam in infants and children. Antimicrob Agents Chemother 38: 2817-2826. [Crossref]
33. Ferraris L, Butel MJ, Aires J (2010) Antimicrobial susceptibility and resistance determinants of Clostridium butyricum isolates from preterm infants. Int J Antimicrob Agents 36: 420-423.

34. Senel S, Karacan C, Erkek N, Gol N (2010) A single-center experience of antimicrobial resistance patterns in pediatric urinary tract infection. Med Princ Pract 19: 359-363.

35. Yildiz B, Kural N, Durmaz G, Yarar C, Ak I, et al. (2007) Antibiotic resistance in children with complicated urinary tract infection. Saudi Med J 28: 1850-1854.

36. Konaté A, Dembélé R, Guessennd NK, Kouadio FK, et al. (2017) Epidemiology and Antibiotic Resistance Phenotypes of Diarrheagenic Escherichia Coli Responsible for Infantile Gastroenteritis in Ouagadougou, Burkina Faso. Eur J Microbiol Immunol (Bp) 7: 168-175. [Crossref]

37. Sydenham TV, Jensen BH, Petersen AM, Krogfelt KA, Justesen US (2017) Antimicrobial resistance in the Bacteroides fragilis group in faecal microbiota from healthy Danish children. Int J Antimicrob Agents 49: 573-578.

38. Ibrahim IA, Al-Shwaikh RM, Ismaeil MI (2014) Virulence and antimicrobial resistance of Escherichia coli isolated from Tigris River and children diarrhea. Infect Drug Resist 7: $317-322$

39. Koren J, Curová K, Kmetová M, Siegfried L, Jankó V, et al. (2013) Involvement of virulence properties and antibiotic resistance in Escherichia coli strains causing pyelonephritis in children. Folia Microbiol 58: 53-59.

40. Marchaim D, Zaidenstein R, Lazarovitch T, Karpuch Y, Ziv T, et al. (2008) Epidemiology of bacteremia episodes in a single center: increase in Gram-negative isolates, antibiotics resistance, and patient age. Eur J Clin Microbiol Infect Dis 27 1045-1051.

41. Rotimi VO, Salako NO, Mokaddas E, Philip L, Rajan P (2005) High frequency of isolation of antibiotic-resistant oral Viridans streptococci from children in Kuwait. $J$ Chemother 17: 493-501.

42. Dzierzanowska D, Lopaciuk U, Kaminska W, Wieczynska J, Pawinska A, et al. (1995) Antibiotic resistance of bacterial strains isolated from children in Child Health Center, Warsaw. Int J Antimicrob Agents 5:179-182.

Copyright: (C2019 Pacifici GM. This is an open-access article distributed under the terms of the Creative Commons Attribution License, which permits unrestricted use, distribution, and reproduction in any medium, provided the original author and source are credited. 